\title{
Polyphenols: Natural Antioxidants to Be Used as a Quality Tool in Wine Authenticity
}

\author{
Alexandros Tzachristas ${ }^{1}$, Konstantina Pasvanka ${ }^{1}$, Antony Calokerinos ${ }^{2}$ (D) and \\ Charalampos Proestos $1, *$ (iD)
}

1 Department of Chemistry, Food Chemistry Laboratory, School of Sciences, National and Kapodistrian University of Athens, 15784 Athens, Greece; A.Tzachristas@chem.uoa.gr (A.T.); pasvankakon@chem.uoa.gr (K.P.)

2 Department of Chemistry, Analytical Chemistry Laboratory, School of Sciences National and Kapodistrian University of Athens, 15784 Athens, Greece; calokerinos@chem.uoa.gr

* Correspondence: harpro@chem.uoa.gr; Tel.: +30-2107274160

Received: 25 July 2020; Accepted: 24 August 2020; Published: 26 August 2020

\begin{abstract}
Polyphenols are a diverse group of compounds possessing various health-promoting properties that are of utmost importance for many wine sensory attributes. Apart from genetic and environmental parameters, the implementation of specific oenological practices as well as the subsequent storage conditions deeply affect the content and nature of the polyphenols present in wine. However, polyphenols are effectively employed in authenticity studies. Provision of authentic wines to the market has always been a prerequisite meaning that the declarations on the wine label should mirror the composition and provenance of this intriguing product. Nonetheless, multiple cases of intentional or unintentional wine mislabeling have been recorded alarming wine consumers who demand for strict controls safeguarding wine authenticity. The emergence of novel platforms employing instrumentation of exceptional selectivity and sensitivity along with the use of advanced chemometrics such as NMR (nuclear magnetic resonance)- and MS (mass spectrometry)-based metabolomics is considered as a powerful asset towards wine authentication.
\end{abstract}

Keywords: polyphenols; wine authenticity; metabolomics; oenological practices; biomarkers

\section{Introduction}

Polyphenols constitute a diverse group of bioactive compounds occurring in both grapes and wines [1]. In plants, they have been found to exhibit key roles in growth, fertility, and reproduction. They present protective properties against abiotic stress conditions such as UV-light and biotic stresses such as pathogen and predator attacks [2,3]. Polyphenols exhibit a significant role in modern food technology and human nutrition [4,5] and are frequently key ingredients in functional foods. The benefits derived from the moderated wine consumption for human health have been well elaborated [6,7] with several groups of phenolic compounds including stilbenes [8], flavonols [9], and proanthocyanidins [10] found to exert various health-promoting properties [6].

Wine production is regulated by OIV (International Organization of Vine and Wine), global wine policies, and national governments. Provision of authentic wines to the market has always been a prerequisite meaning that the declarations on the wine label should mirror the composition and provenance of this intriguing product [11]. However multiple cases of intentional or unintentional wine mislabeling [12-15] have been recorded, alarming wine consumers who demand for strict controls safeguarding wine transparency.

Polyphenols play a fundamental role in the determination of wine sensory attributes contributing greatly to its color, flavor, and taste. In wine trade, the organoleptic characteristics are the major 
determinants of wine consumers' acceptance and preference. It is generally accepted that high-quality red wines exhibit sensory properties that reflect their chemical composition.

Wine is a complex matrix composed of molecules of diverse nature, significantly influenced by environmental factors, as well as viticultural and oenological management approaches. Concerning the latter, various winemaking practices are implemented that play a key role in the composition of the final product. As a result, wine fraud detection can become a challenging task. It has been reported that specific phenolic compounds can be employed as markers in authenticity verification [16].

It is important to investigate the parameters that affect wine composition and to develop reliable methods for wine authenticity. Common applications of wet chemistry or basic chromatographic applications are widely used in routine analysis of phenolic compounds in wine. Nowadays, emerging platforms including mass spectrometry (MS)-based or nuclear magnetic resonance (NMR) metabolomics are considered the current trend in wine authenticity studies. The use of instrumentation of exceptional selectivity and sensitivity combined with advanced multivariate methods of analysis (MVA) for efficient data mining have permitted a thorough characterization of the wine chemical profile often employing polyphenolic compounds as discriminant markers among studied groups.

The aim of this review is to provide updated knowledge regarding the contribution of polyphenols in wine authenticity rotating around three axes. Initially, we present updated data on the polyphenolic composition of grape and wine according to current and earlier studies. Basic structures as well as novel findings are highlighted. Subsequently, we briefly describe the technological approaches implemented for enhanced polyphenol extraction and stability in modern winemaking. This section is included in order to increase the understanding in relation to the extent of the influence of these practices toward wine authenticity. In the last section, studies are presented employing emerging analytical platforms aiming in the provision of in-depth information relating to intra-/inter-varietal aspects as well as vini/viticultural process monitoring.

\section{Structural Information}

From a structural aspect, polyphenols can be divided into two main categories, the flavonoids that bear a common $\mathrm{C}_{6}-\mathrm{C}_{3}-\mathrm{C}_{6}$ skeleton and the non-flavonoids. Their name comes from the Greek (Ancient) word polus (that means "much, many") and phenol, which refers to a chemical structure formed by the attachment of a hydroxyl (-OH) group to an aromatic benzenoid (phenyl) ring in a similar way to that found in alcohols. This section highlights the basic polyphenolic structures in relation to wine authenticity, however, it does not provide a detailed presentation of the polyphenolic profile of grapes and wine as this has been extensively described [17-20].

\subsection{Non-Flavonoid Polyphenols}

Essentially non-flavonoid polyphenols are located in the grape pulp with the main classes comprising of phenolic acids and stilbenes as well as their derivatives. In wine, oak-derived non-flavonoids have also been detected including the classes of hydrolysable tannins (gallotannins and elagitannins), coumarins, and lignans [21,22].

\subsubsection{Phenolic Acids and Derivatives}

Phenolic acids have been successfully employed for white wine authentication purposes [16]. They are divided into two groups, the hydroxybenzoic (HBA) and the hydroxycinnamic (HCA) acids (phenolic acids). HBAs share a common C6-C1 structure, referring to a benzene ring with one carbon aliphatic chain substituent. Different acids are formed by the substitution of the benzene ring, with p-hydroxybenzoic, protocatechuic, syringic, vanillic, and gallic acid regarded as the most abundant compounds in this sub-class Figure 1 [17]. HCAs have been detected and identified in both grapes and wines [23]. They are present in lower concentrations in their free form (ferulic, caffeic, p-coumaric, and sinapic acid) and as esters of tartaric acid (fertaric, caftaric, and coutaric acids) [24,25]. HCAs are the principal phenolic compounds of free-run juice and white wines [26]. High concentration 
of HCAs may provoke a slightly astringent mouthfeel [27]. Esters of gallic acid (gallotannins) and ellagic acid (ellagitannins) with glucose or related sugars are oak-derived non-flavonoids occurring in wine [28]. Ethyl esters [24] as well as various glycosides of other HBAs and HCAs have also been reported [29].<smiles>CCCCCCCCCCO</smiles>

\section{Acids}

protocatechuic

p-hydroxybenzoic Syringic vanillic gallic

$\begin{array}{llll}\mathrm{R} 1 & \mathrm{R} 2 & \mathrm{R} 3 & \mathrm{R} 4 \\ \mathrm{H} & \mathrm{OH} & \mathrm{OH} & \mathrm{H} \\ \mathrm{H} & \mathrm{H} & \mathrm{OH} & \mathrm{H} \\ \mathrm{H} & \mathrm{OCH}_{3} & \mathrm{OH} & \mathrm{OCH} \\ \mathrm{H} & \mathrm{OCH}_{3} & \mathrm{OH} & \mathrm{H} \\ \mathrm{H} & \mathrm{OH} & \mathrm{OH} & \mathrm{OH}\end{array}$

\section{Hydroxycinnamic Acids}

caffeic

-coumaric

sinapic

ferulic

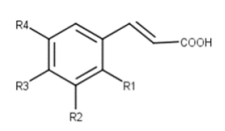

Hydroxycinnamoyltartaric Acids

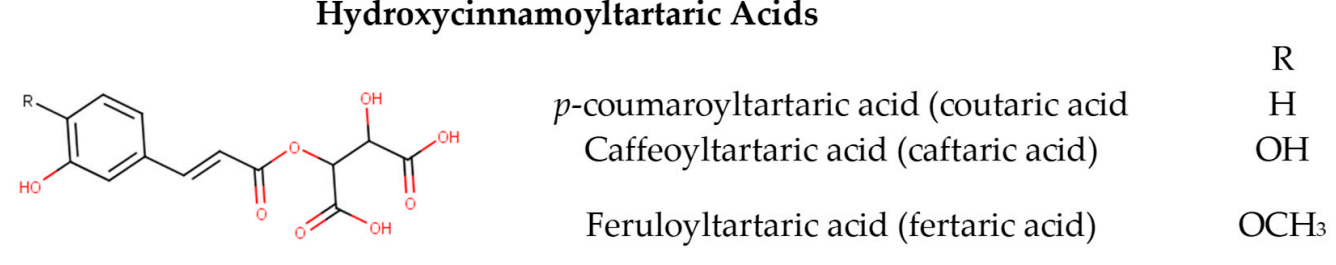

Figure 1. Basic structures of phenolic acids in wine.

\subsubsection{Stilbenes}

Stilbenes are polyphenols featuring diverse biological properties and a complex structure that exhibits a limited but heterogeneous distribution in the plant kingdom [30]. Grapes are one of the richest sources of stilbenes that have also been detected in wines and oak wood. They share a common $C_{6}-C_{2}-C_{6}$ skeleton, containing two benzene rings, usually bonded by an ethylene, or ethane chain. Resveratrol as well as specific oligomers collectively mentioned as "inducible" phytoalexins are produced by the grapevine as a defense response against pathogens [31] (Figure 2). Conversely "metabolized" viniferins are formed by enzymes released from pathogens in an attempt to eliminate toxic compounds [32]. Stilbenes are present as mono-, di-, and trimers and very complex oligomers. Resveratrol is probably the most studied compound of this subclass as it exhibits various therapeutic effects [33-37]. Studies have shown that resveratrol mimics effects of caloric restriction, exerts antioxidative anti-inflammatory properties, and is linked with the initiation and progression of many diseases through several mechanisms [37]. However, the major drawback as reported in most of the clinical trials is its poor bioavailability [37]. Resveratrol content is regulated by genetic and environmental factors. Viticultural practices aiming at lower yields as well as soft vinification protocols can promote/maintain the resveratrol content in wine [31]. Most monomer stilbenes in Vitis species are found as glycosylated or methoxylated derivatives of piceatannol and resveratrol [38]. Apart from trans-resveratrol they include trans and cis piceid (3,4'-5-Trihydroxystilbene-3-beta-D-glucopyranoside), pterostilbene (trans-3,5-dimethoxy-4'-hydroxystilbene), piceatannol (3,4,3',5'-tetrahydroxy-trans-stilbene), and astringin (piceatannol 3-O-beta-D-glucoside). Dimer stilbenes usually contain a monomer resveratrol moety with the most commonly occurring compound being $\varepsilon$-viniferin. Figure 2 depicts a scheme of the formation of resveratrol oligomers and viniferins, initially reported from Bavaresco et al. (2016) [31]. Flamini et al. (2016) reported a significant increase of resveratrol (trans monomer, dimers, and two tetramers) and a simultaneous decrease in glycoside derivatives on Aspergillus. Carbonarious inoculated Negro Amaro cv grapes [32]. Pentamers of resveratrol have been found present in other plants but not in the Vitis vinifera [38]. Papastamoulis et al. (2014) reported the presence of the resveratrol hexamer Viniphenol A in vine stalks of $V$. vinifera [39]. 

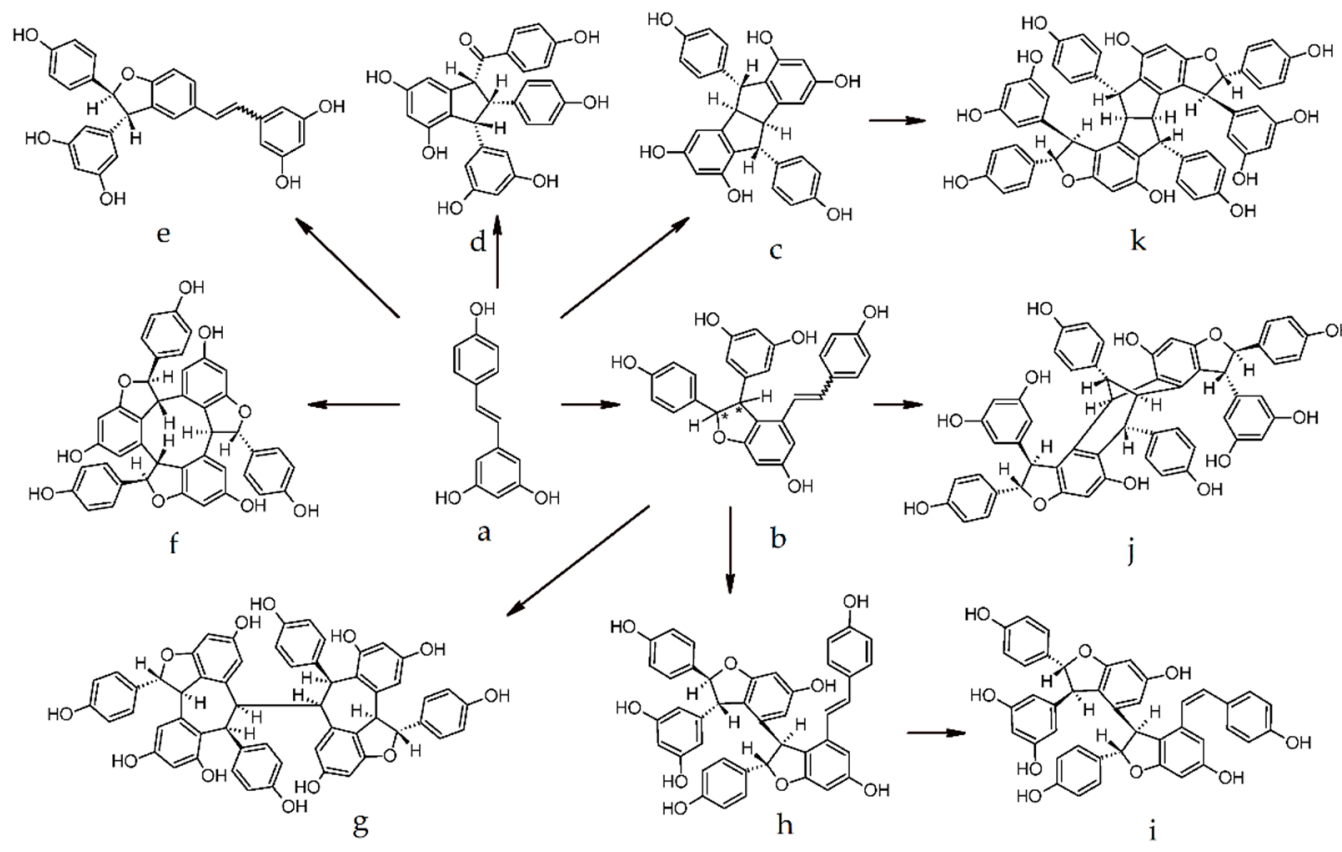

c

$\mathrm{k}$

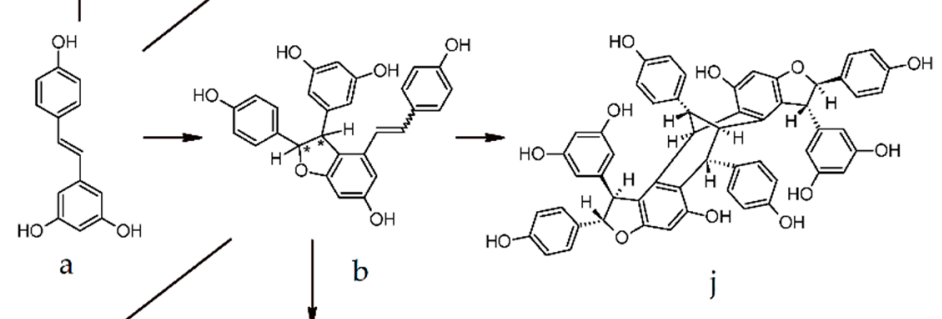

Figure 2. Scheme of formation of resveratrol oligomers and viniferins: (a) trans-resveratrol; (b) (E and Z) $\varepsilon$-viniferin/ $\omega$-viniferin; (c) pallidol; (d) caraphenol B; (e) $\delta$-viniferin (E and Z); (f) $\alpha$-viniferin; (g) isohopeaphenol; (h) E-miyabenol C; (i) Z-miyabenol C; (j) vaticanol C isomer; and (k) ampelopsin H (from Barbaresco et al. (2016) [31]).

\subsubsection{Lignans}

Lignans are an important class of non-flavonoid secondary metabolites occurring in various plants. They are synthesized from shikimic acid through the phenylpropanoid pathway. The amount of lignans in wine has been found to vary on average from $0.22 \mathrm{mg} / \mathrm{L}$ for the whites to $0.80 \mathrm{mg} / \mathrm{L}$ for the reds constituting wine as an important source of lignans in comparison to other alcoholic beverages [21]. Selected compounds including some lignan and neolignan derivatives from lariciresinol, isolariciresinol, and secoisolariciresinol have been previously identified in both white and red wines [22,40].

\subsection{Flavonoid Compounds}

Flavonoids are secondary metabolites occurring in a wide variety of natural products such as vegetables, fruits, stems, cocoa, tea, grapes, and wine. Nowadays flavonoids are considered essential ingredients for various medicinal, nutraceutical, pharmaceutical, and cosmetic applications. This is due to their potent anti-oxidative, anti-carcinogenic, anti-inflammatory, and anti-mutagenic properties combined with the ability to modulate significant enzyme functions [41-43]. In plants they are involved in a series of processes related to defense against pathogens and pests, protection from ultraviolet (UV) radiation, allelopathy, pollen fertilization, auxin transport regulation, and pigmentation [44-47]. In wine, flavonoids have a fundamental role in the determination of its sensory attributes specifically wine color, flavor, astringency, and bitterness [27,48]. Total phenolic content in red wine ranges from 1200 to $1800 \mathrm{mg}$ gallic acid equivalents/L, which is six to nine times more than the corresponding content in white wines [49].

Chemically, they belong to a class displaying a diphenylpropane skeleton structure, essentially, two aromatic rings (rings $\mathrm{A}$ and $\mathrm{B}$ ) linked by a three-carbon chain forming a closed pyran ring (heterocyclic ring containing oxygen, the $C$ ring) with the $A$ aromatic ring (Figure 3 ). In this $C_{6}-C_{3}-C_{6}$ structure, usually the $\mathrm{B}$ aromatic ring is attached to position 2 of $\mathrm{C}$ ring and on fewer occasions, it is found attached to positions 3 or $4[7,17]$. The above possible combinations, the patterns of glycosylation and/or hydroxylation of the aromatic rings, the structural features of the rings, along with the degree of unsaturation and oxidation of the $\mathrm{C}$ ring account for the large diversity of the flavonoid compounds. 


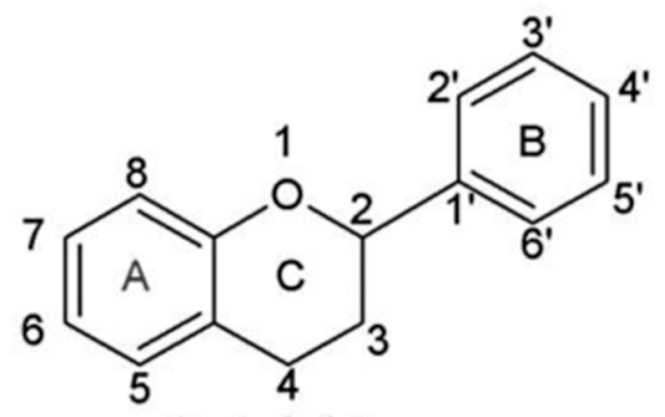

Figure 3. Basic flavonoid structure.

With the exception of chalcones, flavonoids can be subdivided into various types of compounds according to the degree of oxidation of the central ring. Flavonoid compounds where the $\mathrm{B}$ ring is attached to position 3 or 4 of the central ring are called isoflavones and neoflavonoids, respectively. Numerous compounds arise from the attachment of ring B in position 2 of the central ring. The corresponding subgroups are called: flavonols, flavones, flavanonols, flavanones, flavan-3-ols, and anthocyanins. Flavonoids where the central ring is open are chalcones.

Two pathways are involved in the biosynthesis of flavonoids; the shikimate and the acetate (or polyketide) pathway. Ring A and the linking chain (central ring) are synthesized from four $p$-coumaroyl-CoA molecules provided by phenylalanine through the shikimate pathway while the acetate pathway provides three malonyl-CoA molecules derived from glucose transformation and form ring B [45,46]. The two rings are condensated forming chalcone, which followingly is transformed to flavanone. This is the starting unit for the biosynthesis of more than 5000 compounds.

An overview of the main flavonoid groups in grapes and wines is presented in Figure 4.

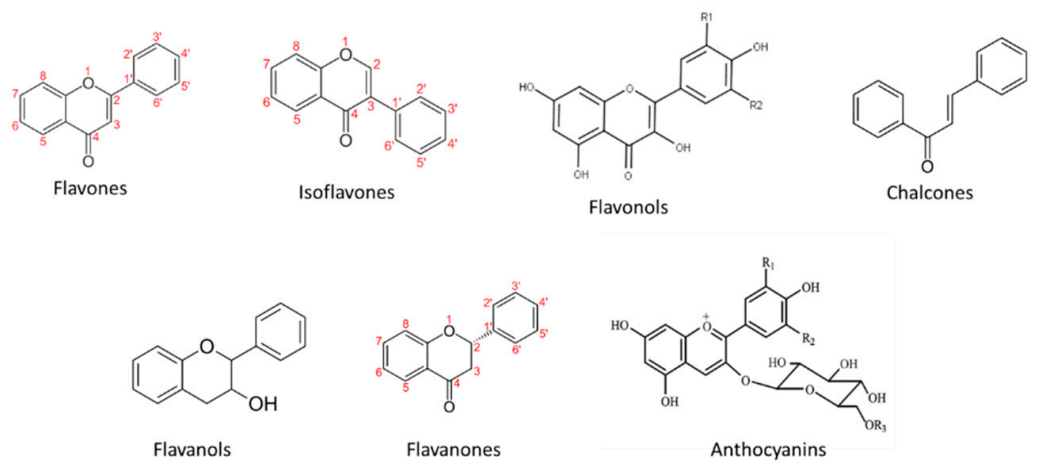

Figure 4. Main flavonoid groups.

\subsubsection{Flavones}

Flavones display a double bond between positions 2 and 3 of the central ring and ketone group at position 4 (Figure 4). They are considered as an important group of various fruits and vegetables. Flavones are present as aglycons and glucosides, however, they are not found abundant in grapes except for luteolin derivatives [50]. Luteolin has been found to exhibit significant anti-oxidative, anti-tumor, cardioprotective, and anti-inflammatory properties [51].

Isoflavones are isomers of flavones where ring B is attached in position 3 of the central ring. Genistein and daidzein are compounds of this subclass found present in wine [52].

\subsubsection{Flavanones}

Flavanones, also called dihydroflavones, display a saturated carbon chain meaning that the double bond between positions 2 and 3 is saturated in comparison to flavones. Eriodictyol, naringenin, and hesperitin are the main compounds identified in grapes and wine from this subclass $[17,25,53-55]$. 


\subsubsection{Flavonols}

Flavonols are a diverse group of flavonoids present in the majority of higher plants. They are mainly localized in the outer epidermis of the grape berry skins and accumulate after flowering and during ripening [9,44]. They exhibit photo-protection and copigmentation properties [9], have been employed for chemotaxonomical studies [56-58], and feature various health-promoting properties [6]. Flavonols are considered as the building blocks for anthocyanins. Structurally, they are characterized by the presence of a double bond in positions 2 and 3 and a ketone group at position 4 of the central ring as well 2 hydroxyl groups at position 5 and 7 of Ring A. Various compounds arise from the different methylation, hydroxylation, and glycosylation patterns observed, constituting flavonols as one of the most important and diverse subclasses of phenolic compounds present in grapes and wine.

In grapes they are commonly found as glycosides of the six main aglycons namely quercetin, kaempferol, isorhamnetin, myricetin, laricitrin, and syringetin (Figure 5). Castillo-Muñoz et al. (2010) reported that in the white grape varieties studied, flavonols were only found present as 3-O-glycoside derivatives, comprising of the series of 3-O-glucosides, 3-O-galactosides, and 3-O-glucuronides of quercetin and kaempferol along with 3-O-glucosides and 3-O-galactosides of isorhamnetin. In the same study, rutin was also detected as well as scarce traces of isorhamnetin 3-O-glucuronide, while myricetin, laricitrin, syringetin, and their derivatives were absent in all samples [56]. The latter absence has been attributed to the lack of expression of the enzyme flavonoid 3',5'-hydroxylase in white grapes $[9,59]$. Mattivi et al. reported that quercetin derivatives were by far the predominant flavonols in white and light rose grape varieties, while myricetin was the most abundant flavonol in the red varieties studied [59]. However, Blancquaert et al. (2019) reported that the major flavonol glucosides of Cabernet Sauvignon grapes from Stellenbosch University vineyard were quercetin-3-O-glucoside and quercetin-3-O-glucuronide and not myricetin derivatives as previously described. The same authors reported that flavonol accumulation was greatly influenced by light quality [44], which was also verified from Martínez-Lüscher et al. (2019) who in hand indicated that flavonol profile is a reliable indicator to assess canopy architecture and exposure of red wines to solar radiation [60]. Favre' et al. (2018) employing HRMS (high-resolution mass spectrometry) metabolomics identified new acetylated and $p$-coumaroylated derivatives of the flavonol 3-O-glucosides of isorhamnetin, laricitrin, and syringetin in Vitis vinifera grape skins and wines [61].

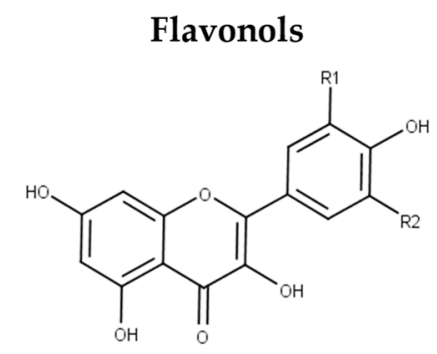

$\begin{array}{ccc} & \mathrm{R} 1 & \mathrm{R} 2 \\ \text { Quercetin } & -\mathrm{OH} & -\mathrm{H} \\ \text { Kaempferol } & -\mathrm{H} & -\mathrm{H} \\ \text { Isorhamnetin } & -\mathrm{OCH}_{3} & -\mathrm{H} \\ \text { Myricetin } & -\mathrm{OH} & -\mathrm{OH} \\ \text { Laricitrin } & -\mathrm{OCH}_{3} & -\mathrm{OH} \\ \text { Syringetin } & -\mathrm{OCH}_{3} & -\mathrm{OCH}_{3}\end{array}$

Figure 5. Structure of the six main flavonol aglycons.

\subsubsection{Flavan-3-ols}

Flavan-3-ols, also named as flavanols or catechins, are mainly located in the solid parts of the berry (stem, skin, seeds), with seeds presenting the highest concentration [62]. Structurally monomeric flavan-3-ols are benzopyrans displaying a carbon chain between $C_{2}$ and $C_{3}$, a hydroxyl group at position three of the central ring, and absence of carbonyl moiety in position 4 [17]. Flavanols possess two chiral carbons, able to form four diastereoisomers for each of them. In Vitis vinifera grape varieties, $(+)$-catechin and (-)-epicatechin are the principal compounds followed by (+)-gallocatechin, $(-)$-epigallocatechin, and the galloylated form of (-)-epicatechin (i.e., (-)-epicatechin gallate), which is found at lower concentrations $[18,63]$ (Figure 6). Flavan-3-ols are responsible for influencing the mouthfeel of wines imparting astringency. This tactile sensation results from flavanol interaction with 
salivary proteins and glycoproteins causing a loss of lubricating power loss of the saliva or with the glycoproteins of the mouth epithylium [64]. It has been reported that flavanol bitterness decreases from the monomer to trimer flavan-3-ols.

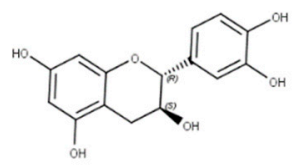

(+)-catechin

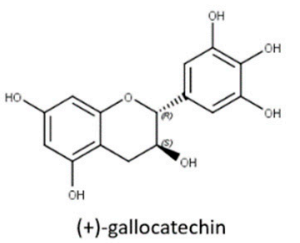

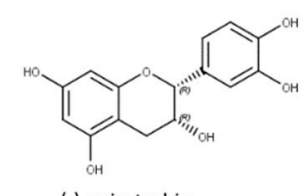

(-)-epicatechin<smiles>OC1Cc2ccccc2OC1c1ccccc1</smiles>

Flavan-3-ols<smiles>C[C@@H]1Cc2c(O)cc(O)cc2O[C@@H]1c1cc(O)c(O)c(O)c1</smiles>

(-)-epigallocatechin

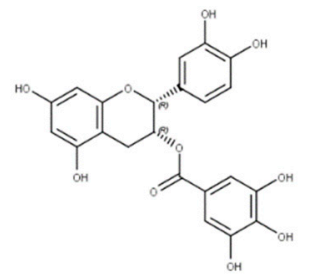

(-)-epicatechin gallate

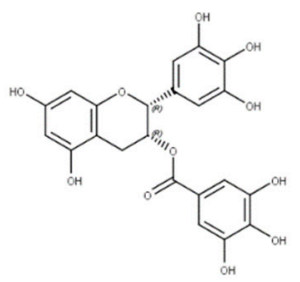

(-)-epigallocatechin gallate

Figure 6. Flavan-3-ol monomeric forms.

Oligomeric and polymeric forms can occur by condensation of the monomeric flavan-3-ols, which are called proanthocyanidins or condensed tannins. Proanthocyanidins have the ability to release anthocyanidins under heated acidic conditions resulting from the cleavage of the interflavanic bond. In Vitis vinifera varieties, proanthocyanidins are further separated into procyanidins and prodelphinidins that comprise of (epi)catechin and (epi)gallocatechin monomeric units, respectively, as well as (-)-epicatechin-3-O-gallate subunits. Both groups are present in the skins and wines while procyanidins are localized only in grape seeds [18]. Proanthocyanidins are further distinguished by the length of the proanthocyanidin chain, into oligomers with mean degree of polymerization $(\mathrm{mDP})$ lower than 5 and polymers $(\mathrm{mDP}>5)$ and by the type of the interflavanic bond into A or $\mathrm{B}$ type procyanidins as extensively described in past studies $[17,18,64]$. The $\mathrm{mDP}$ can vary from two or three subunits to over 30, meaning that compound with a mDP of 10 contains 10 flavan-3-ol subunits in it. The mDP values of skin, seed, and wine flavan-3-ols can vary greatly and are mostly influenced by maturity stage and seasonal variation thus they cannot be considered as a marker for varietal discrimination $[65,66]$. Unlike the mDP index, that subunit composition of skin and wine proanthocyanidins exhibit a strong correlation possibly due to the presence of prodelphinidin subunits [65]. Taking into consideration that the amount of skin and seed proanthocyanidins extracted in the wine is greatly influenced by grape variety, it can be suggested that wine proanthocyanidin composition can be grape variety-dependent [66]. Petropoulos et al. (2017) conducted a comparative study on the proanthocyanidin content of cv. Agiorgitiko from various vineyards in the Nemea PDO (Protected Designation of Origin) region in Greece, providing useful insight on the diversity of this grape variety [65].

Browning of white wines and flavanol content are closely linked. Flavanol auto-oxidation and condensation with glyoxylic acid formed from the oxidative cleavage of tartaric acid have been shown to contribute to the browning process $[64,67]$. The latter process gives rise to new xanthylium derivatives (ranging in color from yellow to orange), which further degrade during storage in various conditions. Buhrle et al. (2017) report that despite the low perception threshold observed, xanthylium derivatives might have no direct impact on white wine color, however, they may influence color formation as intermediate products in polymerization and browning [67]. 
Glycosylated flavanol derivatives (monoglycosides and diglycosides) have been also identified in grape skins and seeds $[63,68]$. Perez-Navarro et al. (2019) employing high-resolution mass spectrometry (HRMS) instrumentation reported the detection of twenty monomeric flavanol monoglycosides, four diglycosylated monomers, and three dimeric flavanol monoglycosides, mainly derivatives of (epi)catechin and (epi)gallocatechin in 6 grape varieties from Spain. Monomeric forms were found more abundant than the corresponding dimeric ones. The same authors suggested a strong influence of grape tissue and cultivar on the profile of the glycosylated flavanols as well as a relation between the latter and berry color in red varieties [63].

"Crown" procyanidins are a novel sub-class of oligomeric cyclic condensed tannins that have been lately identified and characterized in grape and wine and may contribute to wine authenticity studies [69]. The name "crown" was attributed due to their unusual macrocyclic carbon skeleton. Zeng et al. (2019) reported that a specific crown procyanidin tetramer with a molecular formula of $\mathrm{C}_{60} \mathrm{H}_{48} \mathrm{O}_{24}$ appeared to be specifically present only in grape skin, while the oligomeric and polymeric procyanidins were present in bunch stem, skin, and seed. Furthermore, the specific compound exhibited promising protective effects against amyloid- $\beta$-induced toxicity [69].

\subsubsection{Anthocyanins}

Anthocyanins present an essential role in red wines as they impact on wine color as well as on reactions affecting the stability and longevity of red wines [70]. More than 540 anthocyanin pigments have been found in nature [70]. They exhibit a wide range of biological activities including antioxidant, anti-inflammatory, antimicrobial, antimutagenic, and anticarcinogenic properties [71]. In V. vinifera grape varieties, they are mainly localized on red berry skins where they are synthesized from veraison until full ripening. Their content is significantly affected by vintage and overall vineyard management practices [9]. They have been also found present on the skins of some pink-skinned varieties such as Gewurtztraminer and Muscat Rouge de Madere [59] and in the pulp of the so called "teinturer" $V$ vinifera (i.e., Alicante Bouchet) and non V. vinifera grape varieties [72-74].

Malvidin, delphinidin, peonidin, cyanidin, petunidin, and lately pelargonidin $[75,76]$ are regarded as the most important anthocyanidins in wine (Figure 7). Their differentiation lies in the substituent groups present in the B-ring. In Vitis vinifera grape varieties, the aglycon (anthocyanidin) is bonded through a glycosidic bond in position 3 of the ring $C$ to a sugar moiety, commonly glucose. Malvidin-3-O-glucoside has been proposed as the dominant anthocyanin in red grape varieties $[17,44,59,62]$. Moreover, acylation can occur on the glucose moiety with aromatic (such as caffeic, ferulic, sinapic, and $p$-coumaric acids) or aliphatic acids (such as acetic, malic, malonic, oxalic, and succinic acids) probably due to the presence of the enzyme anthocyanin acyl-transferase [9].

Anthocyanins

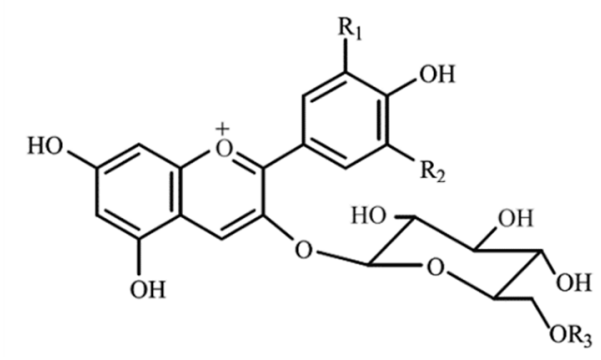

$\begin{array}{lll}\text { Anthocyanidin } & \mathbf{R} 1 & \text { R2 } \\ \text { Malvidin } & \mathrm{OCH}_{3} & \mathrm{OCH} H_{3} \\ \text { Petunidin } & \mathrm{OCH}_{3} & \mathrm{OH} \\ \text { Peonidin } & \mathrm{OCH}_{3} & \mathrm{H} \\ \text { Delphindin } & \mathrm{OH} & \mathrm{OH} \\ \text { Cyanidin } & \mathrm{OH} & \mathrm{H}\end{array}$

R3 = acetyl;p-coumaroyl;caffeoyl

Figure 7. Main anthocyanin chemical structures.

In winemaking, their extraction during maceration reaches a plateau before the end of the fermentation [49] with their concentration in young red wines typically ranging from 200 to $400 \mathrm{mg} / \mathrm{L}$ [49]. During wine maturation and aging, free form anthocyanin concentration declines constantly as they are involved in reactions between them and/or components such as proanthocyanidins and simple 
flavan-3-ols, forming more complex and stable products while affecting wine color and organoleptic characteristics [75]. These reactions mainly include:

- Self-association and co-pigmentation (short-term mechanisms),

- Polymeric anthocyanins with proanthocyanidins and 3-flavanols (long-term mechanisms) and

- New formed compounds, such as pyranoanthocyanins and their polymerized compounds.

Anthocyanins comparing to other flavonoid compounds do not intrinsically affect bitterness or astringency [77]. Although they have no odor or flavor, they can act in synergy with some aroma substances and influence wine flavor [78].

Regarding red vinification practices, it has been recently proposed that oxygen improves cycloaddition and enhances the formation of pyranoanthocyanins, while high microxygenation rates and lower $\mathrm{pH}$ values enhance flavanol-pyranoanthocyanin contents. Moreover, micro-oxygenated red wines have been found richer in Vitisin A in comparison to the control [79].

In recent studies on non-Saccharomyces strains such as Lachancea thermotolerans, an intense effect of some strains was observed on anthocyanin color and stability by strongly reducing wine $\mathrm{pH}$ during the alcoholic fermentation [80]. In addition, selected Saccharomyces yeast strains have been shown to release metabolites such as acetaldehyde or pyruvic acid that promote the formation of Vitisin A and B pyranoanthocyanins during must fermentation [81].

Among phenolics, anthocyanins are regarded as the most successful compounds for red wine varietal authentication [82]. For instance, diglucoside anthocyanins displaying a second glyosidic bond at position $5^{\prime}$ with glucose characterize non- $V$. vinifera grapes and this has been successfully employed in chemotaxonomical studies [9]. The relative proportion of acylated vs. non-acylated anthocyanins is characteristic of each grape variety and has been proposed for cultivar differentiation [83]; however, caution must be taken since these proportions can be modified during the vinification process with the use of pectolytic enzymes or specific maceration conditions [84].

Grape skin phenolic composition can provide valuable information in relation to cultivar differentiation. Recently, Kyraleou et al. (2020) determined the anthocyanin and proanthocyanidin profiles of ninety samples from 5 major Hellenic red grape varieties (Agiorgitiko, Mavrotragano, Mandilaria, Kotsifali, Xinomavro) in two consecutive vintages. The authors reported significant differences in the anthocyanin and proanthocyanidin profiles of skin extracts of different varieties, while this was not observed in the seeds of these varieties [66]. Malvidin-3-O-glucoside was the most abundant anthocyanin in Agiorgitiko, Mavrotragano, Mandilaria, Xinomavro varieties while peonidin-3-O-glucoside in Kotsifali. They also reported that (-)-epicatechin was the main subunit in all grape varieties with the exception of Mavrotragano where (-)-epigallocatechin gallate was the main subunit.

\section{Influence of Vinification Strategies on Wine Polyphenolic Profile}

Polyphenol profile is influenced by genetic and environmental parameters including cultivar, vineyard management practices, seasonal variation, and time of harvest. The subsequent strategies in the early stages of the vinification process including maceration parameters (duration and intensity of turnovers, overall duration, temperature), type of additives used (i.e., enzymes, polysaccharide preparation, phenolic preparations, etc.), fermentation parameters (duration such as temperature and time) affect greatly the extractability and profile of the phenolic compounds having a profound effect on wine quality $[19,23]$. The following section refers to current vinification practices aiming at enhanced pigment extraction and color stability.

\subsection{Pre-Fermentation Juice Runoff}

Pre-fermentation juice runoff, also known as saignée, is an oenological technique where a quantity of juice is racked off prior to the fermentation in order to improve the skin to juice ratio. While fermentation takes place anthocyanins and tannins- present in the seeds and skins-are extracted. 
It has been previously reported that the saignée method influenced wine sensory attributes, by enhancing perceived color intensity, and generally resulting in an increased aroma, flavor, and astringency [85]. Wu et al. (2017) applied the saignée method to a Cabernet Sauvignon winemaking in order to improve the phenolic content in fresh and 1-year aged wines. It was reported that the physicochemical properties of the treated wines were found similar to the corresponding control ones. A moderate but not statistically significant increase in the total non-anthocyanin content was observed.

\subsection{Cold Maceration}

Cold Maceration or more commonly cold soak is essentially a pre-fermentative maceration conducted under low temperatures $\left(4-15^{\circ} \mathrm{C}\right)$ and is designed to enhance aromas, pigments, and tannins from the skins to the wine. In their recent review, Aleixandre-Tudo and du Toit (2018) foresee an even more extreme practice where the low temperatures adopted will allow for the freezing of intra-cellular liquids. This effect will cause breakdown and disorganization of the cell walls, improving the extractability of the intra-vacuolar and intra-cellular phenolic components. However, the economic implications of this practice must be taken seriously into consideration. It must be noted though that the prolonged duration of this procedure rises winery management issues, which are not always preferable.

\subsection{Thermovinification and Flash Release}

Thermovinification is a temperature-dependent traditional process [86] mainly applied to cultivars with low amounts of anthocyanins or in the case of problematic vintages with diseased grapes. In this process, heating is applied on intact or crushed grapes to $60-80{ }^{\circ} \mathrm{C}$ for $30-40 \mathrm{~min}$ by immersion in hot grape juice $[87,88]$. In the case of flash release, the grapes undergo vapor mediated heating at higher temperatures $\left(85-95^{\circ} \mathrm{C}\right)$ followed by a subsequent application of high vacuum. Recent reports regarding thermal pre-fermentative processes focus on several subjects including the characterization of suspended solids in thermo-treated red musts [80,89], the use of non-Saccharomyces yeast species and oenological tannins [90], and the monitoring of anthocyanins and proanthocyanidins evolution during the fermentation of thermo-treated musts by different Saccharomyces cerevisiae Strains [91].

\subsection{Carbonic Maceration}

Vinification by carbonic maceration (CM) is an 80-year-old traditional process exploiting the adaptability of intact grape berries to an oxygen-deprived medium saturated with carbon dioxide [92]. Initially, the produced CM wines were destined for early consumption as they often presented low color intensity, low tannin concentration, low glycerol amount, higher $\mathrm{pH}$ but a rounder mouthfeel, and more intense fruity profile than their conventional counterparts [58,92]. Newer studies are suggesting that CM wines are characterized by high microbial diversity [93], higher total content of aromatic esters and acetates, higher polyphenol content, higher antioxidant activity, and an increase in specific pyranoathocyanidins [94]. Zhang et al. (2020) concluded that a CM Muscat Hamburg wine exhibited higher concentration of volatile compounds, higher odor activity values, and higher sensory ratings [95], while González-Lázaro et al. (2020) reported that the use of CM and pectolytic enzymes was not able to replace conventional vinification for the production of red sparkling wines [96].

\subsection{Enhancement of Copigmentation}

As extensively reported, anthocyanins are highly unstable and prone to oxidation by physicochemical factors including temperature, light, oxygen, $\mathrm{pH}$, and solvents [76]. Copigmentation is in essence, the formation of non-covalent complexes between anthocyanins or an anthocyanidin derived pigment with another cofactor (copigment) [97]. Qualified copigments should present sufficiently extended $\pi$-conjugated systems and hydrogen bond donor/acceptor groups such as hydroxyl of carbonyl groups [97]. Main natural copigments include flavones, (dihydro-)flavonols, flavanols, aminoacids, hydroxycinnamic acids, and derivatives [75]. Copigmentation accounts for $30-50 \%$ of the total color in young red wines thus it is considered as an efficient manner to ameliorate color intensity 
and stability $[98,99]$. Current research efforts target the copigmentation mechanism $[76,98,100,101]$, the physicochemical factors involved, and their optimization [101-103] as well as the anthocyanin interaction with different copigments [102-105].

\subsection{Pectolytic Enzymes}

Enzymes have been widely employed in the beverage industry for various biotransformation purposes. The use of commercial enzymatic preparations present quantitative (elevated juice yields), qualitative (improved pigment extraction and flavor amelioration), and processing advantages (shorter maceration times, reduced energy consumption, limited settling and filtration time) [106]. Enzymatic hydrolytic activity of mixture enzymatic preparations is greatly influenced by their proportions, composition, and the types of enzymatic activity of each of the constituents. Carbohydrases (cellulase and pectinase) are considered the most frequently employed enzymatic classic in novel extraction methods. Fernández et al. (2015) reported that the use of a pectinase-based enzymatic preparation on $V$. vinifera L. 'Pais' grapes presented better efficiency in releasing skin total phenols in comparison to cellulase and tannase [107]. Process optimization is advised as the outcome when using different types of pectolytic enzymes is not always guaranteed.

\subsection{Yeast Selection and Yeast Cell Walls}

During vinification, the polyphenol profile can be influenced by different yeast strains or addition of yeast cell walls, however, relevant literature is still considered limited [108]. Mannoproteins, which are bound to polysaccharides, chitins, and glucanase, compose the yeast cell wall [23]. Due to the different polarities and the hydrophilic or hydrophobic nature of the cell wall polymers, they are capable of retaining or adsorbing different wine constituents, such as volatile compounds or pigments [19]. Moreover, anthocyanins can be absorbed by the cell walls of various yeast strains in a different way. Yeast adsorbed anthocyanin profile through the fermentation process is quite variable [81]. Specific pigments that are attached to dead yeast cells are removed during racking wines off their lees [109]. Elaborated studies revealed that pyranoanthocyanins were weakly adsorbed while acylated anthocyanins were strongly adsorbed compared to non-acylated anthocyanins [76]. Medina-Plaza et al. (2019) investigated cell wall-anthocyanin interactions on a model wine and reported that more than $90 \%$ of the anthocyanin adsorption took place within the first $60 \mathrm{~min}$ of the addition of anthocyanins to cell wall materials while desorption occurred only in $30 \mathrm{~min}$. In addition, anthocyanins with increased degree of methoxylation were adsorbed better in comparison with the hydroxylated ones, which proved that adsorption involves hydrophobic interaction [110]. Studies also focus on the sequential inoculation of different yeasts including both Saccharomyces and non-Saccharomyces species.

\subsection{Non-Thermal Strategies}

The majority of the temperature-mediated processes mentioned above have the major drawback of high energy consumption. Significant drawbacks from the application of these processes have been reported including poor color stability, loss of varietal aromas, and limited aging aptitude of the resulting wines along with the need for starter culture additions, and the high energy demand [111]. Currently, several methods collectively characterized as non-thermal or physical methods have emerged that support polyphenol extraction. These methods include the use of pulsed electric fields [111-114], ultrasound-assisted extraction [111,112], high hydrostatic pressure [113], and nanofiltration [115-117], which have the benefit of shortening maceration duration while improving polyphenol extractability through the rupture of skin cell walls. Indicatevely, Andrés Maza et al. (2019) reported that wines treated with Pulsed electric fields (PEF) $\left(4.0 \mathrm{kV} \mathrm{cm}^{-1}\right.$; flowrate $\left.2500 \mathrm{~kg} \mathrm{~h}^{-1}\right)$ exerted higher values of total anthocyanin, total polyphenolic and tannin content, and color intensity in lower maceration duration in comparison to the corresponding untreated ones [118]. Morata et al. (2015) reported improved anthocyanin extraction and total phenol content, higher levels of methanol and ethanol, and higher sensory indices after comparing treated and untreated wines with high hydrostatic pressure. Nioi et al. (2020) evaluated the effect of nanofiltration in comparison to thermovinification in Pinot 
noir wine making. They concluded that nanofiltration was comparable to thermovinification in terms of total phenols content and color intensity values and that different membranes presented better anthocyanin extraction and higher overall sensory ratings [115].

Non-thermal strategies have additional benefits including the potential to synergistically reduce $\mathrm{SO}_{2}$ levels, to be used in various stages of the vinification process, and the possibility to conduct fermentations with wild yeast populations [111]. Evidently, synergies between (novel and traditional) extraction methods should also be considered.

\section{Current Analytical Approaches to Wine Authenticity}

\subsection{Overview}

Conventional methods of wet chemistry or basic applications of liquid chromatography are widely used in the determination of wine polyphenols as these procedures are part of the official methods of analysis [119]. However, the emergence of disciplines such as HRMS or NMR metabolomics combined with advanced chemometric techniques has been proven as a powerful tool to perform chemotaxonomic studies through identification of numerous grape and wine metabolites [120]. Metabolomics is a field involved in the study of multiple metabolites in a cell, a tissue, or an organism. The precise structure determination provided by NMR or the extensive metabolite coverage of MS-based metabolomics are among the properties that have made them the two most popular disciplines in food authenticity. Both, however, have limitations as described in detail in previous reports [120-122].

Metabolomic studies are divided into two main platforms: the targeted and non-targeted or untargeted approaches. Targeted metabolomics is hypothesis testing approaches that aim at the detection, identification, and quantification of a specific group of compounds. They usually require a sample preparation step (though minimal in most cases) and subsequent optimization and validation studies as well as the provision of adequate purity commercial standards. Non-target or untargeted screening (NTS) approaches are "unbiased" hypothesis-generating approaches that focus on the comprehensive detection and (putative) annotation of multiple endogenous and exogenous low-molecular-weight $(<1 \mathrm{kDa})$ molecules/metabolites in a biological system. Suspect screening metabolomics is a midway approach [123] where specific mass to charge ratios are targeted in the absence of commercial standards based on literature or mass spectral bases.

Current scientific efforts on wine authenticity aim to unveil significant information in various grape and wine-related aspects including variety and origin verification as well as process monitoring by detecting and identifying characteristic patterns or markers for each aspect [124]. The purpose of this section is to present the contemporary methods platforms approved by the OIV regarding wine quality and, in consequence, highlight current research findings focusing on polyphenolic compounds and wine authenticity.

\subsection{Official Wine Analytical Methods}

Traditional wine analytical methods involve multidisciplinary approaches in order to assess wine quality and authenticity. Only the official methods published in the OIV's Compendium of International Methods of Analysis of Wines and Musts are applicable for verification purposes and settling disputes. Official wine analytical methods include the determination of: alcoholic strength (ethanol) [125], reducing substances [126], total and volatile acidity [127,128], total and free sulfur dioxide [129], volatile compounds by gas chromatography (GC) [130], principal organic acid concentration by high-pressure capillary electrophoresis [131], mineral elements by inductive plasma atomic emission spectrometry [132], ethanol origin by isotope ratio mass spectrometry [133] and ethanol deuterium distribution by NMR [134]. Regulatory authorities also assess wine for the presence of artificial sweeteners [135] or colorants [136], preservatives as well as fermentation inhibitors [137].

Regarding the study of polyphenols in wine authenticity studies, the Folin-Ciocalteau index is the OIV reference method for the determination of all compounds with a phenolic structure 
(total phenols) and it is used in the European Union (EU) as the official method of analysis [138]. The official methods of analysis also include the determination of the five most important non-acylated anthocyanins and the four major acylated anthocyanins by reversed-phase liquid chromatography (RP-LC) HPLC [139] as well as the determination of the possible presence of malvidin diglycoside by fluorescence spectroscopy [140]. In any case, OIV encourages member states to continue research in the areas of interest to avoid any non-scientific evaluation of results.

\subsection{Studies Focusing on Varietal or Geographical Origin Discrimination}

Chemotaxonomical studies employing polyphenolic compounds mainly focus on (intra-, inter-) varietal/geographical origin characterization, discrimination as well fraud detection. As the data provided by the analytical platforms do not often solely target polyphenolic compounds, in modern studies polyphenolic substances are part of the compounds that contribute to class separation. Most recently, Arapitsas et al. (2020) provided the characterization of the metabolome of 11 single-cultivar, single-vintage Italian red wines with the use of untargeted HRMS metabolomics. In this significant study, among other biomarkers, quercetin was found more abundant in Sangiovese wines followed by Nebiolo and Nerello, isorhamnetin was more abundant in Nebiolo wines, while anthocyanin content was found higher in Teroldego wines [124]. Regarding grapes from the same variety, Locatelli et al. (2016) reported that Nebiollo wine samples evidenced significant differences in grape anthocyanin profile in comparison to Uva Rara and Vespolina cv. varieties enabling their classification [141].

Several studies have been conducted worldwide contributing to wine authenticity assessment. Concerning Argentinian wines, Pisano et al. (2015) employing HRMS metabolomics reported that three malvidin-derived anthocyanins contributed significantly to the geographical and varietal discrimination of 27 wines samples [142]. Rosso et al. (2018) also employing HRMS metabolomics proposed a method based on the calculation of secondary metabolite indexes namely (dihydro-)flavonols and anthocyanin ratios, to identify the unauthorized use of Primitivo and Negro Amaro grapes in the production of Valpolicella wines. They showed that the addition of Primitivo in the blend could be detected as it increased the indexes related to Laricitrin, Delphinidin, and Petunidin. [143]. Geana et al. (2016) reported that the abundance in the acylated glucoside of malvidin, as well as the ratios between the latter and the glucoside of malvidin along with the ratio between acylated and coumarilated monoglucosides of peonidin and malvidin were among the most significant variables, which enabled for varietal classification of 62 Romanian red wines. The same authors additionally reported that individual acylated and non-acylated anthocyanins as well as specific anthocyanin ratios contributed to vintage classification. Recently, Stoj et al. (2020) investigated the classification of 20 Polish red wines produced from Zweigelt (Vitis vinifera) and Rondo (non-Vitis vinifera) grape varieties based on the analysis of phenolic compounds by means of Ultra Performance Liquid Chromatography (UPLC) with a photo diode array detector (PDA) coupled to mass spectrometry. As expected, the non Vitis vinifera cultivar exhibited higher concentrations of anthocyanin diglucosides while in the $V$. vinifera variety the anthocyanin monoglucosides were found in greater abundance. An interesting finding of this study was that anthocyanin diglucosides were also found present even in low concentrations in the V. vinifera Zweigelt grape variety [144]. The latter evidence is in agreement with a relatively recent work from Xing et al. (2015) questioning earlier reports that denoted the absence of these compounds in V. vinifera varieties $[9,19]$.

$\mathrm{Hu}$ et al. (2020) employed proton-nuclear magnetic resonance instrumentation ( $\left.{ }^{1} \mathrm{H}-\mathrm{NMR}\right)$ combined with multivariate statistical analysis to investigate the changes of metabolite levels in Cabernet Sauvignon, Merlot, and Cabernet Gernischt Chinese dry red wines. In this study, gallic acid was among the significant markers discriminating the grape varieties.

Savino et al. (2017) investigated the intra-varietal diversity of Aglianico cv. secondary metabolites including anthocyanins, flavonols, flavanols, and resveratrol, identifying significant differences among the accessions studied [145]. 
Reports on phenolic compounds mostly refer to red wines. However, polyphenolic compounds have also been found to contribute to rose' or white wine classification. Gil et al. (2020) discriminated rosé wines using shotgun metabolomics with a genetic algorithm and MS ion intensity ratios. They focused on polyphenols and reported that the compounds used for discrimination were vanillic acid, peonidin 3-O-acetyl-Glucoside-(epi)catechin, peonidin 3-O-Glucoside, and (epi)catechin-ethyl-(epi)catechin isomers [146]. Roschetti et al. (2018), applying untargeted metabolomics coupled to multivariate methods of analysis, investigated the phenolic composition of Chardonnay wines from different origins [147]. Flavonoids and, in particular flavonols, were found to be the best markers in relation to geographical origin. It must be noted, however, that the number of samples in this study was limited $(n=6)$ and half of the samples were oak aged.

Long et al. (2019) investigated the distribution of a novel crown hexameric procyanidin and its tetrameric and pentameric congeners in Italian red and white wines by means of HPLC-HRMS/MS (High-Performance Liquid Chromatography-High Resolution Tandem Mass Spectrometry) [148]. They reported the presence of a crown hexameric procyanidin only in the red wines examined, while crown tetramer and pentamer procyanidins were also present in white wines. Regarding the white wines examined, cyclic pentameric procyanidin was absent in Gewürztraminer samples while in Sauvignon Blanc and Chardonnay samples, the pentameric procyanidin was found present solely in its cyclic form. The authors suggested that the proportions of crown 4-, 5-, and 6-mer procyanidins are grape variety dependent and demonstrated that crown procyanidins may act as a tool in wine authenticity studies.

\subsection{Process Monitoring}

The last decade emerging disciplines have enabled thorough monitoring of the various processes involved in viticulture and enology. Below we present examples of process/treatment monitoring related studies involving polyphenolic compounds in viticulture and wine. Wine evolution studies may offer valuable information regarding process-related authentication including age evaluation or proper storage verification.

Seasonal variability, rootstock as well vine training system are among the factors that affect polyphenol composition. Alves Filho et al. (2019) combined ${ }^{1} \mathrm{H}$ NMR and Ultra Performance Liquid Chromatography-Mass Spectrometry (UPLC-MS)-based metabolomic approach coupled to advance chemometrics to evaluate the variability in Chenin Blanc and Syrah wines for two harvest seasons, two vine training systems and six rootstocks. They reported that wines produced from espalier training system were more abundant in caffeic acid derivatives while wines produced from a lyre system resulted in increased quantities in phenolic compounds, organic acids, and apocarotenoids [149].

There is an increasing demand for more sustainable management practices mainly organic and biodynamic farming protocols. "Eco"-friendly wines are frequently marketed at higher prices that are indirectly attributed to claimed health benefits. So far though, the results regarding the phenolic composition of wines from these "alternative" management protocols are contradictory. Tassoni et al. (2013) concluded that no significant differences were observed among samples coming from conventional, organic, and biodynamic management protocols [150]. Picone et al. (2016) reported that caffeic and coumaric acids, as well as other polyphenolic compounds, were in lower abundance in biodynamic grapes than in organic ones. Furthermore, it has been reported that concentration of total polyphenols and anthocyanins was found higher in organic wines in comparison to their biodynamic counterparts [151,152]. However, in a more recent report from Parpinello et al. (2019), it was stated that no statistically significant differences were observed regarding the concentrations of anthocyanins, flavonols, phenolic, and cinnamic acids between organic and biodynamic wines [153]. Nonetheless, it must be stated that polyphenol composition cannot be easily compared between different agronomical treatments as it is severely influenced by genetic and environmental factors [23].

A number of studies target wine evolution. Various pigments and tannins have been identified among discriminant biomarkers for micro-oxygenated Sangiovese wines versus non-micro-oxygenated 
ones [154]. In another study, Herbert-Pucheta et al. (2019) studied wine chemistry involved in aging processes, employing a set of mono-varietal Queretaro Merlot samples as model system. With the use of Ultraviolet Visible (UV-VIS) absorbance-transmittance coupled with excitation emission matrix fluorescence, they discovered a rich (poly)-phenolics aromatic region, which was subsequently confirmed with NMR experiments [155].

Proper storage conditions are considered fundamental for preserving wine sensory attributes and this is considered a prerequisite for wine enthusiasts and especially wine retailers. In this context, Arapitsas et al. (2016) developed a holistic metabolic profiling method using hydrophilic interaction chromatography (HILIC) mass spectrometry to study the effect of typical domestic storage conditions as compared to optimum cellar conditions for five Sangiovese red wines and for a period of 24 months. They reported that quercetin, catechin, malvidin 3-glucoside, and pyranomalvidin 3-glucoside were among the marker compounds affected by the different storage conditions. Quercetin was found richer for domestic storage that was derived from the hydrolysis of quercetin 3-glucoside in these conditions, while the latter three were more abundant in the case of optimum cellar storage [156].

The study of the evolution of anthocyanins and tannins during wine aging is considered a challenging task due to their vast structural diversity, low abundance, and the fact that many of these metabolites exhibit similar or identical mass spectral characteristics. Therefore, chromatographic separation is fundamental and the combination between separation modes may provide valuable insight. In this direction, Willemse et al. (2015) applied online HILIC $\times$ reversed-phase liquid chromatography (RP-LC) separation coupled to high-resolution mass spectrometry and characterized in detail the anthocyanin and derived pigments content of one and six year oldo Pinotage wine [157]. The authors reported the putative identification of ninety-four (94) anthocyanin-derived pigments and enhanced certainty in compound identification. It is expected that multi-dimensional platforms (i.e., GC $\times$ GC or LC $\times$ LC) will be widely applied in wine authenticity and metabolomic studies, as they increase the number of peaks and enhance resolution, selectivity, and sensitivity compared to conventional chromatographic approaches [158].

Roullier-Gall et al. (2019) combined electrochemical oxidation strategies and ultra-high-resolution Fourier transform ion cyclotron resonance mass spectrometry (FT-ICR-MS) in order to characterize from an untargeted molecular point of view, the antioxidant property of 7-year-old Chardonnay wines only differing in $\mathrm{SO}_{2}$ added after prior pressing. They concluded that apart from known metabolites such as catechin/epicatechin and caffeic acid, sulfur-containing compounds appeared to decrease with electrochemical oxidation, whereas nitrogen-containing compounds were mostly formed [159].

Gougeon et al. (2019) performed quantitative ${ }^{1} \mathrm{H}$ NMR experiments on 224 commercial wines produced in the six major Bordeaux appellations and quantified 40 metabolites. Multivariate data analysis and advanced chemometrics allowed the discrimination of wines on different levels (young vs. old wines; Bordeaux vs. French wines; wines from different Bordeaux appellations) [160]. The authors stated that among the compounds responsible for vintage discrimination, catechin and epicatechin were more abundant in younger vintages while the opposite was true for caffeic and syringic acid. As stated in the previous sections, catechin and epicatechin are involved in a series of polymerization reactions with other compounds reducing their free form abundance explaining the latter finding.

Gougeon et al. (2019) performed a real case study on wine authentication, evaluating the complementarity of a q-NMR method with classical multidisciplinary approaches. The analyzed samples belonged to three categories (a) half bottled wines topped up with wine of different origin, (b) suspect wine samples from the foreign market, and (c) authentic samples [161]. They developed a similarity score index in order to compare authentic with suspect wine samples. Catechin, epicatechin, gallic, and syringic acids were among the phenolic compounds evaluated as possible authenticity markers. The authors also demonstrated the synergy between the methods examined. Table 1 depicts a collection of studies involving polyphenols that contribute to wine authenticity assessment. 
Table 1. Collection of studies involving polyphenols that contribute to wine authenticity assessment.

\begin{tabular}{|c|c|c|c|c|c|c|c|c|c|c|c|c|c|}
\hline No. & $\begin{array}{c}\text { Sample } \\
\text { Type }\end{array}$ & $\mathrm{n}$ & Country & An. Platform & $\begin{array}{l}\text { Ion } \\
\text { Mode }\end{array}$ & Type & Research Aim & VP & GO & AP & $\begin{array}{c}\text { Polyphenols as Significant } \\
\text { Markers }\end{array}$ & $\begin{array}{l}\text { Statistical } \\
\text { Analysis }\end{array}$ & Ref \\
\hline 1 & Wine & 110 & Italy & UPLC-QTOF MS & Pos, neg & NT & $\begin{array}{c}\text { LC-MS metabolomic } \\
\text { fingerprint of } 11 \\
\text { mono-cultivar Italian red } \\
\text { wines-metabolomic } \\
\text { similarity-dissimilarity } \\
\text { study. }\end{array}$ & $\mathrm{x}$ & $\mathrm{x}$ & & $\begin{array}{l}\text { Holistic approach with specific } \\
\text { flavonols (Quercetin, Isorhametin) } \\
\text { and anthocyanins as markers }\end{array}$ & PCA & [124] \\
\hline 2 & Wine & 20 & Poland & UPLC-PDA-MS/MS & Pos, Neg & $\mathrm{T}$ & $\begin{array}{l}\text { Classification of Red Wines } \\
\text { Produced from Zweigelt } \\
\text { and Rondo Grape Varieties } \\
\text { Based on the Analysis of } \\
\text { Phenolic Compounds by } \\
\text { UPLC-PDA-MS/MS. }\end{array}$ & $\mathrm{x}$ & $\mathrm{x}$ & & $\begin{array}{l}\text { Anthocyanin mono (malvidin } \\
\text { 3-O-glucoside, delphinidin } \\
\text { 3-O-glucoside, petunidin } \\
\text { 3-O-glucoside)- and di- glucosides } \\
\text { (malvidin diglucoside, peonidin } \\
\text { diglucoside, delphinidin di } \\
\text { glucoside), flavan-3ols }\end{array}$ & PCA, HCA & [144] \\
\hline 3 & Wine & 60 & France & UPLC-QTOF-MS & Pos & $\mathrm{T}$ & $\begin{array}{l}\text { Discrimination of rosé } \\
\text { wines with a genetic } \\
\text { algorithm and MS ion } \\
\text { intensity ratios. }\end{array}$ & & $\mathrm{x}$ & & $\begin{array}{c}\text { Vanillic acid, Peonidin } \\
\text { 3-O-acetyl-glucoside-(epi)catechin, } \\
\text { Peonidin 3-O-Glucoside and (epi) } \\
\text { catechin-ethyl-(epi)catechin } \\
\text { isomers }\end{array}$ & GA, RF, LDA & [146] \\
\hline 4 & Wine & 19 & Italy & $\begin{array}{c}\text { HPLC } \\
\text {-DAD-MS-MS }\end{array}$ & Pos, Neg & $\mathrm{T}$ & $\begin{array}{l}\text { Distribution of crown } \\
\text { hexameric procyanidin and } \\
\text { its tetrameric and } \\
\text { pentameric congeners in } \\
\text { red and white wines. }\end{array}$ & $\mathrm{x}$ & & & $\begin{array}{l}\text { Ratios between crown and } \\
\text { non-cyclic procyanidins }\end{array}$ & $\begin{array}{l}\text { ANOVA, } \\
\text { PCA }\end{array}$ & [148] \\
\hline 5 & Grapes & 14 & Italy & HPLC -DAD & - & $\mathrm{T}$ & $\begin{array}{c}\text { Detection of Intra-Varietal } \\
\text { Diversity of Aglianico cv } \\
\text { based on differences in the } \\
\text { accumulation of secondary } \\
\text { metabolites. }\end{array}$ & $\mathrm{x}$ & & & $\begin{array}{l}\text { Total anthocyanins, Total } \\
\text { flavonoids, Flavonoids other than } \\
\text { anthocyanins, Total flavonoids in } \\
\text { seeds, Resveratrol and Flavonols }\end{array}$ & $\begin{array}{l}\text { ANOVA, } \\
\text { PCA }\end{array}$ & [145] \\
\hline 6 & Grapes & 14 & Italy & RP-HPLC/DAD & - & $\mathrm{T}$ & $\begin{array}{l}\text { Phenolic composition of } \\
\text { Nebbiolo grape (Vitis } \\
\text { vinifera L.) from Piedmont: } \\
\text { characterization during } \\
\text { ripening of grapes selected } \\
\text { in different geographic } \\
\text { areas and comparison with } \\
\text { Uva Rara and Vespolina cv. }\end{array}$ & $x$ & & & $\begin{array}{l}\text { Major classes mentioned; } \\
\text { Significant differences in } \\
\text { Anthocyanin Profile (e.g., Peonidin } \\
\text { 3-0 Glucoside) among varieties }\end{array}$ & $\begin{array}{l}\text { ANOVA, } \\
\text { PCA, HCPC }\end{array}$ & [141] \\
\hline 7 & $\begin{array}{l}\text { Grape } \\
\text { wine }\end{array}$ & 7 & Italy & $\begin{array}{l}\text { UPLC-MS and } \\
\text { HPLC-DAD }\end{array}$ & & $\mathrm{T}$ & $\begin{array}{l}\text { A survey of red non-V. } \\
\text { vinifera grape metabolites. }\end{array}$ & $\mathrm{x}$ & & & $\begin{array}{l}\text { Anthocyanin mono - and di- } \\
\text { glucosides, proanthocyanidins of } \\
\text { non-V. vinifera genotypes rich in } \\
\text { oligomers and short-chain } \\
\text { polymers }\end{array}$ & PCA & [162] \\
\hline
\end{tabular}


Table 1. Cont.

\begin{tabular}{|c|c|c|c|c|c|c|c|c|c|c|c|c|c|}
\hline No. & $\begin{array}{c}\text { Sample } \\
\text { Type }\end{array}$ & $\mathrm{n}$ & Country & An. Platform & $\begin{array}{l}\text { Ion } \\
\text { Mode }\end{array}$ & Type & Research Aim & VP & GO & AP & $\begin{array}{c}\text { Polyphenols as Significant } \\
\text { Markers }\end{array}$ & $\begin{array}{l}\text { Statistical } \\
\text { Analysis }\end{array}$ & Ref \\
\hline 8 & Grapes & 90 & Greece & HPLC-MS & Pos & $\mathrm{T}$ & $\begin{array}{l}\text { Discrimination of five } \\
\text { Greek red grape varieties } \\
\text { according to the } \\
\text { anthocyanin and } \\
\text { proanthocyanidin profiles } \\
\text { of their skins and seeds. }\end{array}$ & $x$ & & & $\begin{array}{l}\text { Selected skin anthocyanins and } \\
\text { proanthocyanidins }\end{array}$ & $\begin{array}{l}\text { ANOVA, } \\
\text { PCA }\end{array}$ & [66] \\
\hline 9 & Wine & 45 & Italy & UPLC-QTOF MS & Pos & NT & $\begin{array}{l}\text { The effect of storage } \\
\text { conditions on the } \\
\text { metabolite content of } \\
\text { red wines. }\end{array}$ & & & $x$ & $\begin{array}{c}\text { Holistic approach, identified } \\
\text { phenolic compounds: Quercetin, } \\
\text { catechin, malvidin 3-glucoside and } \\
\text { pyranomalvidin 3-glucoside }\end{array}$ & $\begin{array}{c}\text { PCA, } \\
\text { OPLS-DA }\end{array}$ & [156] \\
\hline 10 & Wines & 62 & Romania & HPLC-DAD & - & $\mathrm{T}$ & $\begin{array}{l}\text { Classification of red wines } \\
\text { using suitable markers } \\
\text { coupled with multivariate } \\
\text { statistical analysis. }\end{array}$ & $\mathrm{x}$ & & & $\begin{array}{l}\text { Individual anthocyanins, ratio } \\
\text { between anthocyanins to malvidin, } \\
\text { ratios between acylated and } \\
\text { coumarilated monoglucosides of } \\
\text { peonidin and malvidin }\end{array}$ & LDA & [163] \\
\hline 11 & Grape & 3 & Italy & UPLC-QTOF MS & Pos, Neg & $\mathrm{T}$ & $\begin{array}{l}\text { HRMS metabolomic study } \\
\text { of grape chemical markers } \\
\text { to reveal use of not-allowed } \\
\text { varieties in the production } \\
\text { of Amarone and } \\
\text { Recioto wines. }\end{array}$ & $\mathrm{x}$ & & & $\begin{array}{l}\text { Dihydroflavonols (laricitrin) and } \\
\text { anthocyanin (delphinidin, } \\
\text { petunidin) ratios }\end{array}$ & PCA & [143] \\
\hline 13 & Wine & 3 & France & FT-ICR-MS & & & $\begin{array}{c}\text { Electrochemical triggering } \\
\text { of the Chardonnay wine } \\
\text { metabolome. }\end{array}$ & & & $x$ & $\begin{array}{l}\text { Catechin, epicatechin, caffeic acid } \\
\text { and sulfur-containing compounds }\end{array}$ & ANOVA & [159] \\
\hline 14 & Wine & 224 & France & NMR & & & $\begin{array}{l}\text { The metabolomic profile of } \\
\text { Bordeaux red wines. }\end{array}$ & $\mathrm{x}$ & $x$ & & $\begin{array}{l}\text { Catechin, epicatechin, caffeic acid, } \\
\text { syringic acid, galic acid }\end{array}$ & $\begin{array}{l}\text { OSC-PLS-D, } \\
\text { PCA and } \\
\text { ANOVA }\end{array}$ & [160] \\
\hline 15 & Wine & 19 & China & NMR & & & $\begin{array}{l}\text { Wine Analysis and } \\
\text { Authenticity Using } \\
\text { 1H-NMR Metabolomics } \\
\text { Data: Application to } \\
\text { Chinese Wines. }\end{array}$ & $x$ & $x$ & & Gallic acid, Syringic acid & $\begin{array}{l}\text { ANOVA, } \\
\text { PCA }\end{array}$ & [164] \\
\hline
\end{tabular}


Table 1. Cont.

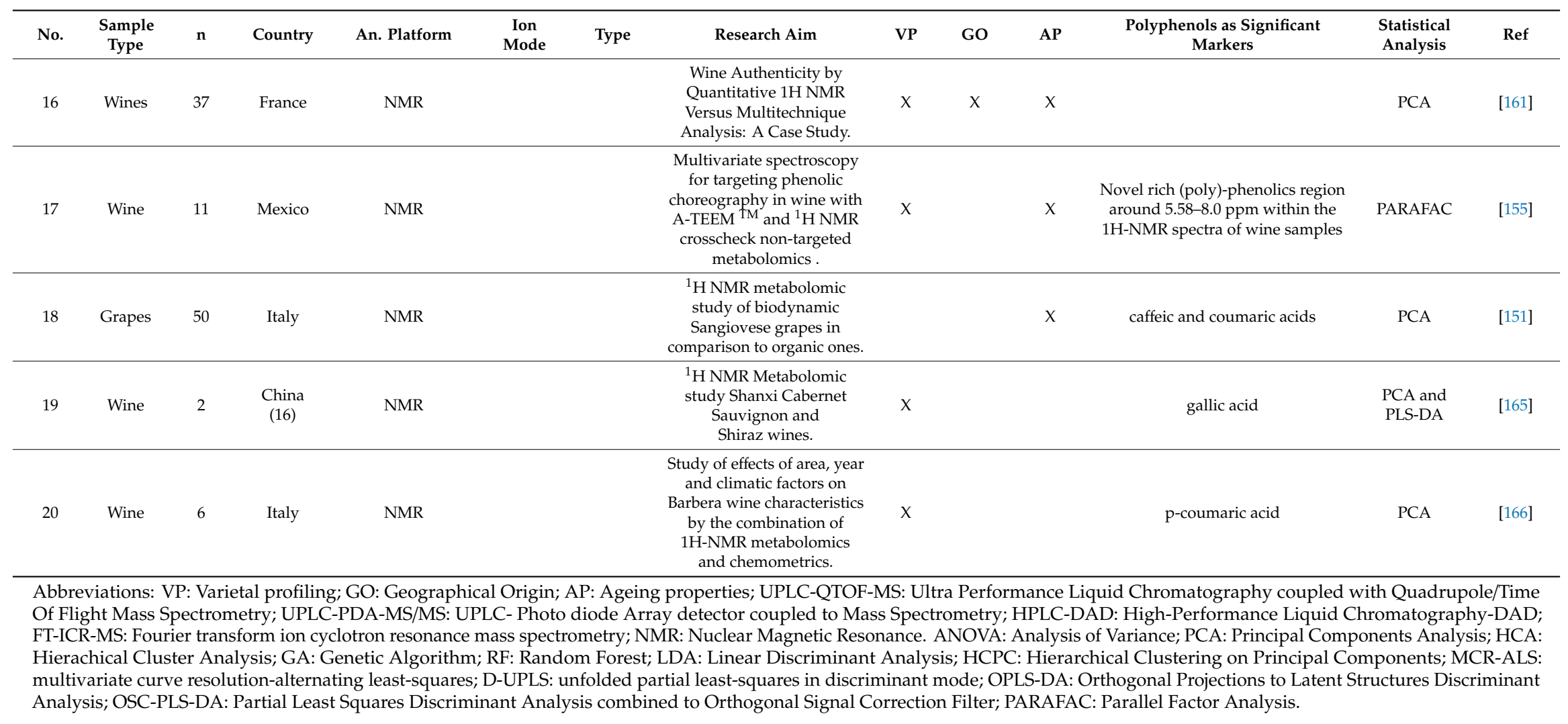




\subsection{Data Processing and Interpretation}

Emerging NMR and MS-based analytical platforms produce a tremendous amount of information, posing nowadays elevated challenges in handling, pre-processing, statistical analysis, visualization, and interpretation of frequently large datasets. The synergy between scientists belonging to different fields including bioinformatics, statistics, computational and data science has given rise to numerous tools and platforms, providing significant resources in this direction.

Metabolomics scientists are able to develop their tools with modern scripting languages such as the open source Python, R, Raku, Ruby, or the commercially available Matlab being considered as the most popular languages in which the scripts are written. Moreover, online platforms are publicly available such as the Metaboanalyst 4.0 (https://www.metaboanalyst.ca) or the Workflow4Metabolomics 3.0 (https://workflow4metabolomics.org), which provide GUI (graphical user interface) solutions for efficient data processing and interpretation of results. Numerous statistical packages are also currently available including EZInfo SIMCA-P (Umetrics, Umea, Sweden), Origin Statistical software (OriginLab Corporation, Northampton, UK) or SPSS (SPSS Inc., Chicago, IL, USA), and Minitab v.14 (Minitab Inc., State College, PA, USA). A detailed presentation of the tools and packages available in each step (pre-processing, statistical analysis, visualization, and interpretation) or approach (targeted-non targeted metabolomics) is beyond the scope of this work and can be found in recent reviews [167-170].

Regarding the statistical analysis of the datasets, tools such as the Hierarchical Cluster Analysis (HCA) and the omnipresent PCA have been traditionally employed for an unbiased search for differential or common trends among samples. However, these approaches are less favorable when searching for discriminative markers among groups. In this case, various supervised methods including partial least squares (PLS) and orthogonal partial least squares (OPLS) discriminant analysis, ANN (artificial neural networks), CVA (canonical variate analysis), SVM (support vector machine) have been previously employed [146,158]. For instance, Portinale et al. (2017) presented an intelligent data analysis approach, based on machine learning techniques for the authenticity assessment of high-quality Nebbiolo-based wines from Piedmont (Italy) [171]. The study employed a total of 158 samples (102 authentic and 56 experimental), analyzing the data derived from spectrophotometric as well as chromatographic characterization of the wine phenolic fraction in both unsupervised and supervised manner. Selected anthocyanins, phenolic acids, stilbenes, and flavonoids served as intrants used for the authenticity assessment.

It must be noted that taking into consideration the diverse experimental design often involved, no generalized standard operation approach for the statistical data mining of such experiments should be suggested [172].

\section{Conclusions}

Polyphenols are a diverse group of compounds of utter importance to wine quality. Current understanding of the polyphenolic composition in wine is well elaborated, however, recent studies continuously report novel findings involving them.

Apart from genetic and environmental factors, polyphenol composition in wine is significantly influenced by winemaking practices. This is greatly reflected upon the composition of the final product constituting wine authentication as a challenging task. In order to better understand the extraction mechanisms, an overview of the current technological practices involved was presented.

Emerging analytical approaches employing instrumentation of exceptional sensitivity combined with advanced chemometric techniques have shed unprecedented light on wine polyphenolic composition. MS-based as well as NMR metabolomics enable for thorough polyphenol profile characterization. Inter- and intra-varietal investigation as well as process monitoring from vine to wine are among the most studied current topics while selected polyphenols have been proved to be effective discriminant biomarkers. Individual phenolic compounds as well as specific phenolic compound ratios have been found to significantly contribute to class separation. It is evident that synergistic approaches 
between emerging analytical platforms in combination with advanced multivariate data analysis will be considered the spearheads toward fraud detection and the provision of authentic wines.

Author Contributions: Conceptualization, A.T. and C.P.; visualization, A.C. and C.P.; writing-original draft, A.T., K.P., and C.P.; writing-review and editing, C.P. and A.C. All authors have read and agreed to the published version of the manuscript.

Funding: This research received no external funding.

Acknowledgments: We would like to thank the two anonymous referees for their valuable comments that have led to a substantial improvement of our work.

Conflicts of Interest: The authors declare no conflict of interest.

\section{References}

1. Proestos, C.; Bakogiannis, A.; Komaitis, M. Determination of Phenolic Compounds in Wines. Int. J. Food Stud. 2012, 1, 33-41. [CrossRef]

2. Yun, J.W.; Lee, W.S.; Kim, M.J.; Lu, J.N.; Kang, M.H.; Kim, H.G.; Kim, D.C.; Choi, E.J.; Choi, J.Y.; Kim, H.G.; et al. Characterization of a profile of the anthocyanins isolated from Vitis coignetiae Pulliat and their anti-invasive activity on HT-29 human colon cancer cells. Food Chem. Toxicol. 2010, 48, 903-909. [CrossRef] [PubMed]

3. Watson, R.R. Polyphenols in Plants: Isolation, Purification and Extract Preparation; Elsevier Inc.: Amsterdam, The Netherlands, 2018; ISBN 9780123979346.

4. Rana, Z.H.; Alam, M.K.; Akhtaruzzaman, M. Nutritional Composition, Total Phenolic Content, Antioxidant and $\alpha$-Amylase Inhibitory Activities of Different Fractions of Selected Wild Edible Plants. Antioxidants 2019, 8, 203. [CrossRef] [PubMed]

5. Alam, M.K.; Rana, Z.H.; Islam, S.N.; Akhtaruzzaman, M. Comparative assessment of nutritional composition, polyphenol profile, antidiabetic and antioxidative properties of selected edible wild plant species of Bangladesh. Food Chem. 2020, 320, 126646. [CrossRef]

6. Golan, R.; Gepner, Y.; Shai, I. Wine and Health-New Evidence. Eur. J. Clin. Nutr. 2019, 72, 55-59. [CrossRef]

7. Bose, S.; Sarkar, D.; Bose, A.; Mandal, S.C. Natural Flavonoids and Its Pharmaceutical Importance. Pharma Rev. 2018, 61-75.

8. Ma, D.S.L.; Tan, L.T.H.; Chan, K.G.; Yap, W.H.; Pusparajah, P.; Chuah, L.H.; Ming, L.C.; Khan, T.M.; Lee, L.H.; Goh, B.H. Resveratrol-potential antibacterial agent against foodborne pathogens. Front. Pharmacol. 2018, 9, 102. [CrossRef]

9. Flamini, R.; Mattivi, F.; De Rosso, M.; Arapitsas, P.; Bavaresco, L. Advanced knowledge of three important classes of grape phenolics: Anthocyanins, stilbenes and flavonols. Int. J. Mol. Sci. 2013, 14, 19651-19669. [CrossRef]

10. Nunes, M.A.; Pimentel, F.; Costa, A.S.G.; Alves, R.C.; Oliveira, M.B.P.P. Cardioprotective properties of grape seed proanthocyanidins: An update. Trends Food Sci. Technol. 2016, 57, 31-39. [CrossRef]

11. European Commission Regulation (EU) No 1308/2013 of the European Parliament and of the Council of 17 December 2013 Establishing a Common Organisation of the Markets in Agricultural Products and Repealing Council Regulations (EEC) No 922/72, (EEC) No 234/79, (EC) No 1037/2001 a. Off. J. Eur. Union Law 2013, L347, 1-184.

12. Holmberg, L. Wine fraud. Int. J. Wine Res. 2010, 2, 105-113. [CrossRef]

13. Muhammad, A.; Countryman, A.M. In Vino 'No' Veritas: Impacts of fraud on wine imports in China. Aust. J. Agric. Resour. Econ. 2019, 63, 742-758. [CrossRef]

14. Fougere, E.; Kaplan, E.K.; Collins, C.A. Pricing uncertainty in wine markets following the Rudy Kurniawan scandal. J. Wine Res. 2020, 31, 1-5. [CrossRef]

15. Geana, E.I.; Popescu, R.; Costinel, D.; Dinca, O.R.; Stefanescu, I.; Ionete, R.E.; Bala, C. Verifying the red wines adulteration through isotopic and chromatographic investigations coupled with multivariate statistic interpretation of the data. Food Control 2016, 62, 1-9. [CrossRef]

16. Pasvanka, K.; Tzachristas, A.; Proestos, C. Quality tools in wine traceability and authenticity. In Quality Control in the Beverage Industry: Volume 17: The Science of Beverages; Elsevier Inc.: Amsterdam, The Netherlands, 2019; Volume 17, pp. 289-334. ISBN 9780128166819. 
17. Garrido, J.; Borges, F. Wine and grape polyphenols-A chemical perspective. Food Res. Int. 2013, 54, 1844-1858. [CrossRef]

18. Monagas, M.; Bartolomé, B.; Gómez-Cordovés, C. Updated knowledge about the presence of phenolic compounds in wine. Crit. Rev. Food Sci. Nutr. 2005, 45, 85-118. [CrossRef]

19. Ribéreau-Gayon, P.; Glories, Y.; Maujean, A.; Dubourdieu, D. Handbook of Enology, The Chemistry of Wine: Stabilization and Treatments: Second Edition; John Wiley \& Sons, Ltd.: Chichester, UK, 2006; Volume 2, ISBN 9780470010396.

20. Palade, L.; Popa, M. Polyphenol Fingerprinting Approaches in Wine Traceability and Authenticity: Assessment and Implications of Red Wines. Beverages 2018, 4, 75. [CrossRef]

21. Rodríguez-García, C.; Sánchez-Quesada, C.; Toledo, E.; Delgado-Rodríguez, M.; Gaforio, J.J. Naturally lignanrich foods: A dietary tool for health promotion? Molecules 2019, 24, 917. [CrossRef]

22. Baderschneider, B.; Winterhalter, P. Isolation and characterization of novel benzoates, cinnamates, flavonoids, and lignans from Riesling wine and screening for antioxidant activity. J. Agric. Food Chem. 2001, 49, 2788-2798. [CrossRef]

23. Jackson, R.S. Wine Science: Principles and Applications; Elsevier Inc.: Amsterdam, The Netherlands, 2020; ISBN 0128165375.

24. Lambert, M.; Meudec, E.; Verbaere, A.; Mazerolles, G.; Wirth, J.; Masson, G.; Cheynier, V.; Sommerer, N. A high-throughput UHPLC-QqQ-MS method for polyphenol profiling in rosé wines. Molecules 2015, 20, 7890-7914. [CrossRef]

25. Vrhovsek, U.; Masuero, D.; Gasperotti, M.; Franceschi, P.; Caputi, L.; Viola, R.; Mattivi, F. A Versatile Targeted Metabolomics Method for the Rapid Quantification of Multiple Classes of Phenolics in Fruits and Beverages. J. Agric. Food Chem. 2012, 60, 8831-8840. [CrossRef] [PubMed]

26. Keller, M. The Science of Grapevines; Elsevier Inc.: Amsterdam, The Netherlands, 2020; ISBN 9780123748812.

27. Gawel, R.; Smith, P.A.; Cicerale, S.; Keast, R. The mouthfeel of white wine. Crit. Rev. Food Sci. Nutr. 2018, 58, 2939-2956. [CrossRef] [PubMed]

28. Oliveira, C.M.; Ferreira, A.C.S.; De Freitas, V.; Silva, A.M.S. Oxidation mechanisms occurring in wines. Food Res. Int. 2011, 44, 1115-1126. [CrossRef]

29. Barnaba, C.; Dellacassa, E.; Nicolini, G.; Nardin, T.; Serra, M.; Larcher, R. Non-targeted glycosidic profiling of international wines using neutral loss-high resolution mass spectrometry. J. Chromatogr. A 2018, 1557, 75-89. [CrossRef]

30. Rivière, C.; Pawlus, A.D.; Mérillon, J.M. Natural stilbenoids: Distribution in the plant kingdom and chemotaxonomic interest in Vitaceae. Nat. Prod. Rep. 2012, 29, 1317-1333. [CrossRef]

31. Bavaresco, L.; Lucini, L.; Busconi, M.; Flamini, R.; De Rosso, M. Wine resveratrol: From the ground up. Nutrients 2016, 8, 222. [CrossRef]

32. Flamini, R.; Zanzotto, A.; de Rosso, M.; Lucchetta, G.; Dalla Vedova, A.; Bavaresco, L. Stilbene oligomer phytoalexins in grape as a response to Aspergillus carbonarius infection. Physiol. Mol. Plant Pathol. 2016, 93, 112-118. [CrossRef]

33. Rodríguez-Cabo, T.; Rodríguez, I.; López, P.; Ramil, M.; Cela, R. Investigation of liquid chromatography quadrupole time-of-flight mass spectrometry performance for identification and determination of hydroxylated stilbene antioxidants in wine. J. Chromatogr. A 2014, 1337, 162-170. [CrossRef]

34. Flamini, R. Mass spectrometry in grape and wine chemistry. Part I: Polyphenols. Mass Spectrom. Rev. 2003, 22, 218-250. [CrossRef]

35. Flamini, R.; De Rosso, M.; Bavaresco, L. Study of grape polyphenols by liquid chromatography-high-resolution mass spectrometry (UHPLC/QTOF) and suspect screening analysis. J. Anal. Methods Chem. 2015, 2015, 350259. [CrossRef]

36. Fernández-Mar, M.I.; Mateos, R.; García-Parrilla, M.C.; Puertas, B.; Cantos-Villar, E. Bioactive compounds in wine: Resveratrol, hydroxytyrosol and melatonin: A review. Food Chem. 2012, 130, 797-813. [CrossRef]

37. Berman, A.Y.; Motechin, R.A.; Wiesenfeld, M.Y.; Holz, M.K. The therapeutic potential of resveratrol: A review of clinical trials. NPJ Precis. Oncol. 2017, 1, 1-9. [CrossRef] [PubMed]

38. Duarte, N.; Ramalhete, C.; Rijo, P.; Reis, M.A.; Ferreira, M.-J.U. Stilbenoids in Grapes and Wine. In Handbook of Dietary Phytochemicals; Xiao, J., Sarker, S.D., Asakawa, Y., Eds.; Springer: Singapore, 2020; pp. 1-28. ISBN 9789811317453. 
39. Papastamoulis, Y.; Richard, T.; Nassra, M.; Badoc, A.; Krisa, S.; Harakat, D.; Monti, J.-P.; Mérillon, J.-M.; Waffo-Teguo, P. Viniphenol A, a complex resveratrol hexamer from Vitis vinifera stalks: Structural elucidation and protective effects against amyloid- $\beta$-induced toxicity in PC12 cells. J. Nat. Prod. 2014, 77, $213-217$. [CrossRef] [PubMed]

40. Marchal, A.; Cretin, B.N.; Sindt, L.; Waffo-Téguo, P.; Dubourdieu, D. Contribution of oak lignans to wine taste: Chemical identification, sensory characterization and quantification. Tetrahedron 2015, 71, 3148-3156. [CrossRef]

41. Swaminathan, M.; Chee, C.F.; Chin, S.P.; Buckle, M.J.C.; Rahman, N.A.; Doughty, S.W.; Chung, L.Y. Flavonoids with M1 muscarinic acetylcholine receptor binding activity. Molecules 2014, 19, 8933-8948. [CrossRef] [PubMed]

42. Silva, A.R.; Grosso, C.; Delerue-Matos, C.; Rocha, J.M. Comprehensive review on the interaction between natural compounds and brain receptors: Benefits and toxicity. Eur. J. Med. Chem. 2019, 174, 87-115. [CrossRef]

43. Jakaria, M.; Azam, S.; Jo, S.-H.; Kim, I.-S.; Dash, R.; Choi, D.-K. Potential Therapeutic Targets of Quercetin and Its Derivatives: Its Role in the Therapy of Cognitive Impairment. J. Clin. Med. 2019, 8, 1789. [CrossRef]

44. Blancquaert, E.H.; Oberholster, A.; Ricardo-da-Silva, J.M.; Deloire, A.J. Grape Flavonoid Evolution and Composition Under Altered Light and Temperature Conditions in Cabernet Sauvignon (Vitis vinifera L.). Front. Plant Sci. 2019, 10, 1062. [CrossRef]

45. Dwivedi, S.; Malik, C.; Chhokar, V. Molecular structure, biological functions, and metabolic regulation of flavonoids. In Plant Biotechnology: Recent Advancements and Developments; Springer: Singapore, 2017; pp. 171-188. ISBN 9789811047329.

46. Nabavi, S.M.; Šamec, D.; Tomczyk, M.; Milella, L.; Russo, D.; Habtemariam, S.; Suntar, I.; Rastrelli, L.; Daglia, M.; Xiao, J.; et al. Flavonoid biosynthetic pathways in plants: Versatile targets for metabolic engineering. Biotechnol. Adv. 2020, 38, 107316. [CrossRef]

47. Baskar, V.; Venkatesh, R.; Ramalingam, S. Flavonoids (antioxidants systems) in higher plants and their response to stresses. In Antioxidants and Antioxidant Enzymes in Higher Plants; Springer International Publishing: New York, NY, USA, 2018; pp. 253-268. ISBN 9783319750880.

48. Soares, S.; Brandão, E.; Mateus, N.; de Freitas, V. Sensorial properties of red wine polyphenols: Astringency and bitterness. Crit. Rev. Food Sci. Nutr. 2017, 57, 937-948. [CrossRef]

49. Kennedy, J.A.; Saucier, C.; Glories, Y. Grape and wine phenolics: History and perspective. Am. J. Enol. Vitic. 2006, 57, 239-248.

50. Hostetler, G.L.; Ralston, R.A.; Schwartz, S.J. Flavones: Food sources, bioavailability, metabolism, and bioactivity. Adv. Nutr. 2017, 8, 423-435. [CrossRef] [PubMed]

51. Luo, Y.; Shang, P.; Li, D. Luteolin: A Flavonoid that has multiple cardio-protective effects and its molecular mechanisms. Front. Pharmacol. 2017, 8, 692. [CrossRef] [PubMed]

52. De Sanctis, F.; Silvestrini, M.G.; Luneia, R.; Botondi, R.; Bellincontro, A.; Mencarelli, F. Postharvest dehydration of wine white grapes to increase genistein, daidzein and the main carotenoids. Food Chem. 2012, 135, 1619-1625. [CrossRef]

53. Mayr, C.; De Rosso, M.; Dalla Vedova, A.; Flamini, R. High-Resolution Mass Spectrometry Identification of Secondary Metabolites in Four Red Grape Varieties Potentially Useful as Traceability Markers of Wines. Beverages 2018, 4, 74. [CrossRef]

54. Sun, J.; Liang, F.; Bin, Y.; Li, P.; Duan, C. Screening non-colored phenolics in red wines using liquid chromatography/ultraviolet and mass spectrometry/mass spectrometry libraries. Molecules 2007, 12, 679-693. [CrossRef]

55. Kennedy, J.A. Grape and wine phenolics: Observations and recent findings. Cienc. Investig. Agrar. 2008, 35, 77-90. [CrossRef]

56. Castillo-Muñoz, N.; Gómez-Alonso, S.; García-Romero, E.; Hermosín-Gutiérrez, I. Flavonol profiles of Vitis vinifera white grape cultivars. J. Food Compos. Anal. 2010, 23, 699-705. [CrossRef]

57. Castillo-Muñoz, N.; Gómez-Alonso, S.; García-Romero, E.; Hermosín-Gutiérrez, I. Flavonol profiles of Vitis vinifera red grapes and their single-cultivar wines. J. Agric. Food Chem. 2007, 55, 992-1002. [CrossRef]

58. Castillo-Sánchez, J.J.; Mejuto, J.C.; Garrido, J.; García-Falcón, S. Influence of wine-making protocol and fining agents on the evolution of the anthocyanin content, colour and general organoleptic quality of Vinhão wines. Food Chem. 2006, 97, 130-136. [CrossRef] 
59. Mattivi, F.; Guzzon, R.; Vrhovsek, U.; Stefanini, M.; Velasco, R. Metabolite profiling of grape: Flavonols and anthocyanins. J. Agric. Food Chem. 2006, 54, 7692-7702. [CrossRef] [PubMed]

60. Martínez-Lüscher, J.; Brillante, L.; Kurtural, S.K. Flavonol Profile Is a Reliable Indicator to Assess Canopy Architecture and the Exposure of Red Wine Grapes to Solar Radiation. Front. Plant Sci. 2019, 10, 10. [CrossRef] [PubMed]

61. Favre, G.; González-Neves, G.; Piccardo, D.; Gómez-Alonso, S.; Pérez-Navarro, J.; Hermosín-Gutiérrez, I. New acylated flavonols identified in Vitis vinifera grapes and wines. Food Res. Int. 2018, 112, 98-107. [CrossRef] [PubMed]

62. Lingua, M.S.; Fabani, M.P.; Wunderlin, D.A.; Baroni, M.V. From grape to wine: Changes in phenolic composition and its influence on antioxidant activity. Food Chem. 2016, 208, 228-238. [CrossRef] [PubMed]

63. Pérez-Navarro, J.; Cazals, G.; Enjalbal, C.; Cañas, P.M.I.; Gómez-Alonso, S.; Saucier, C. Flavanol Glycoside Content of Grape Seeds and Skins of Vitis vinifera Varieties Grown in Castilla-La Mancha, Spain. Molecules 2019, 24, 4001. [CrossRef] [PubMed]

64. Andersen, Ø.M.; Markham, K.R. Flavonoids: Chemistry, Biochemistry and Applications; CRC Press: Boca Raton, FL, USA, 2005; ISBN 9781420039443.

65. Petropoulos, S.; Kanellopoulou, A.; Paraskevopoulos, I.; Kotseridis, Y.; Kallithraka, S. Characterization of grape and wine proanthocyanidins of Agiorgitiko (Vitis vinifera L. cv.) cultivar grown in different regions of Nemea. J. Food Compos. Anal. 2017, 63, 98-110. [CrossRef]

66. Kyraleou, M.; Kallithraka, S.; Gkanidi, E.; Koundouras, S.; Mannion, D.T.; Kilcawley, K.N. Discrimination of five Greek red grape varieties according to the anthocyanin and proanthocyanidin profiles of their skins and seeds. J. Food Compos. Anal. 2020, 92, 103547. [CrossRef]

67. Bührle, F.; Gohl, A.; Weber, F. Impact of Xanthylium Derivatives on the Color of White Wine. Molecules 2017, 22, 1376. [CrossRef]

68. Zerbib, M.; Mazauric, J.P.; Meudec, E.; Le Guernevé, C.; Lepak, A.; Nidetzky, B.; Cheynier, V.; Terrier, N.; Saucier, C. New flavanol O-glycosides in grape and wine. Food Chem. 2018, 266, 441-448. [CrossRef]

69. Zeng, L.; Pons-Mercadé, P.; Richard, T.; Krisa, S.; Teissèdre, P.-L.; Jourdes, M. Crown Procyanidin Tetramer: A Procyanidin with an Unusual Cyclic Skeleton with a Potent Protective Effect against Amyloid- $\beta$-Induced Toxicity. Molecules 2019, 24, 1915. [CrossRef]

70. Wrolstad, R.E.; Durst, R.W.; Lee, J. Tracking color and pigment changes in anthocyanin products. Trends Food Sci. Technol. 2005, 16, 423-428. [CrossRef]

71. De Pascual-Teresa, S.; Moreno, D.A.; García-Viguera, C. Flavanols and anthocyanins in cardiovascular health: A review of current evidence. Int. J. Mol. Sci. 2010, 11, 1679-1703. [CrossRef] [PubMed]

72. Santiago, J.L.; González, I.; Gago, P.; Alonso-Villaverde, V.; Boso, S.; Martínez, M.C. Identification of and relationships among a number of teinturier grapevines that expanded across Europe in the early 20th century. Aust. J. Grape Wine Res. 2008, 14, 223-229.

73. Wu, B.H.; Guan, L.; Li, J.H.; Fan, P.G.; Chen, S.; Fang, J.B.; Li, S.H. Anthocyanin accumulation in various organs of a teinturier cultivar (Vitis vinifera L.) during the growing season. Am. J. Enol. Vitic. 2012, 63, 177-184.

74. Guan, L.; Dai, Z.; Wu, B.H.; Wu, J.; Merlin, I.; Hilbert, G.; Renaud, C.; Gomès, E.; Edwards, E.; Li, S.H.; et al. Anthocyanin biosynthesis is differentially regulated by light in the skin and flesh of white-fleshed and teinturier grape berries. Planta 2016, 243, 23-41. [CrossRef]

75. He, F.; Liang, N.N.; Mu, L.; Pan, Q.H.; Wang, J.; Reeves, M.J.; Duan, C.Q. Anthocyanins and their variation in red wines II. Anthocyanin derived pigments and their color evolution. Molecules 2012, 17, 1483-1519. [CrossRef]

76. He, F.; Liang, N.N.; Mu, L.; Pan, Q.H.; Wang, J.; Reeves, M.J.; Duan, C.Q. Anthocyanins and their variation in red wines I. Monomeric anthocyanins and their color expression. Molecules 2012, 17, 1571-1601. [CrossRef]

77. Vidal, S.; Francis, L.; Williams, P.; Kwiatkowski, M.; Gawel, R.; Cheynier, V.; Waters, E. The mouth-feel properties of polysaccharides and anthocyanins in a wine like medium. Food Chem. 2004, 85, 519-525. [CrossRef]

78. Dufour, C.; Sauvaitre, I. Interactions between anthocyanins and aroma substances in a model system. Effect on the flavor of grape-derived beverages. J. Agric. Food Chem. 2000, 48, 1784-1788. [CrossRef] 
79. Quaglieri, C.; Jourdes, M.; Waffo-Teguo, P.; Teissedre, P.L. Updated knowledge about pyranoanthocyanins: Impact of oxygen on their contents, and contribution in the winemaking process to overall wine color. Trends Food Sci. Technol. 2017, 67, 139-149. [CrossRef]

80. Morata, A.; Loira, I.; Tesfaye, W.; Bañuelos, M.A.; González, C.; Suárez Lepe, J.A. Lachancea thermotolerans applications in wine technology. Fermentation 2018, 4, 53. [CrossRef]

81. Morata, A.; Escott, C.; Loira, I.; Del Fresno, J.M.; González, C.; Suárez-Lepe, J.A. Influence of Saccharomyces and non-Saccharomyces Yeasts in the Formation of Pyranoanthocyanins and Polymeric Pigments during Red Wine Making. Molecules 2019, 24, 4490. [CrossRef]

82. Villano, C.; Lisanti, M.T.; Gambuti, A.; Vecchio, R.; Moio, L.; Frusciante, L.; Aversano, R.; Carputo, D. Wine varietal authentication based on phenolics, volatiles and DNA markers: State of the art, perspectives and drawbacks. Food Control 2017, 80, 1-10. [CrossRef]

83. Versari, A.; Laurie, V.F.; Ricci, A.; Laghi, L.; Parpinello, G.P. Progress in Authentication, Typification and Traceability of Grapes and Wines by Chemometric Approaches; Elsevier Inc.: Amsterdam, The Netherlands, 2014; Volume 60, ISBN 3904573381.

84. Cheynier, V.; Dueñas-Paton, M.; Salas, E.; Maury, C.; Souquet, J.M.; Sarni-Manchado, P.; Fulcrand, H. Structure and properties of wine pigments and tannins. Am. J. Enol. Vitic. 2006, 57, 298-305.

85. Gawel, R.; Iland, P.G.; Leske, P.A.; Dunn, C.G. Compositional and sensory differences in syrah wines following juice run-off prior to fermentation. J. Wine Res. 2001, 12, 5-18. [CrossRef]

86. Lowe, E.J.; Oey, A.; Turner, T.M. Gasquet Thermovinification System Perspective After Two Years' Operation. Am. J. Enol. Vitic. 1976, 27, 130-133.

87. Wang, J.; Huo, S.; Zhang, Y.; Liu, Y.; Fan, W. Effect of different pre-fermentation treatments on polyphenols, color, and volatile compounds of three wine varieties. Food Sci. Biotechnol. 2016, 25, 735-743. [CrossRef] [PubMed]

88. Lukić, I.; Budić-Leto, I.; Bubola, M.; Damijanić, K.; Staver, M. Pre-fermentative cold maceration, saignée, and various thermal treatments as options for modulating volatile aroma and phenol profiles of red wine. Food Chem. 2017, 224, 251-261. [CrossRef]

89. Vernhet, A.; Bes, M.; Bouissou, D.; Carrillo, S.; Brillouet, J.M. Characterization of suspended solids in thermo-treated red musts. J. Int. Sci. Vigne Vin 2016, 50, 9-21. [CrossRef]

90. Chen, K.; Escott, C.; Loira, I.; Del Fresno, J.M.; Morata, A.; Tesfaye, W.; Calderon, F.; Benito, S.; Suárez-Lepe, J.A. The effects of pre-fermentative addition of oenological tannins on wine components and sensorial qualities of red wine. Molecules 2016, 21, 1445. [CrossRef]

91. Vernhet, A.; Carrillo, S.; Rattier, A.; Verbaere, A.; Cheynier, V.; Nguela, J.M. Fate of Anthocyanins and Proanthocyanidins during the Alcoholic Fermentation of Thermovinified Red Musts by Different Saccharomyces cerevisiae Strains. J. Agric. Food Chem. 2020, 68, 3615-3625. [CrossRef] [PubMed]

92. Tesniere, C.; Flanzy, C. Carbonic maceration wines: Characteristics and winemaking process. In Advances in Food and Nutrition Research; Elsevier: Amsterdam, The Netherlands, 2011; Volume 63, pp. 1-15.

93. Guzzon, R.; Malacarne, M.; Larcher, R.; Franciosi, E.; Toffanin, A. The impact of grape processing and carbonic maceration on the microbiota of early stages of winemaking. J. Appl. Microbiol. 2020, 128, 209-224. [CrossRef] [PubMed]

94. González-Arenzana, L.; Santamaría, R.; Escribano-Viana, R.; Portu, J.; Garijo, P.; López-Alfaro, I.; López, R.; Santamaría, P.; Gutiérrez, A.R. Influence of the carbonic maceration winemaking method on the physicochemical, colour, aromatic and microbiological features of tempranillo red wines. Food Chem. 2020, 319, 126569. [CrossRef] [PubMed]

95. Zhang, Y.-S.; Du, G.; Gao, Y.-T.; Wang, L.-W.; Meng, D.; Li, B.-J.; Brennan, C.; Wang, M.-Y.; Zhao, H.; Wang, S.-Y. The effect of carbonic maceration during winemaking on the color, aroma and sensory properties of 'Muscat Hamburg'wine. Molecules 2019, 24, 3120. [CrossRef] [PubMed]

96. González-Lázaro, M.; Martínez-Lapuente, L.; Guadalupe, Z.; Ayestaran, B.; Bueno-Herrera, M.; López de la Cuesta, P.; Pérez-Magariño, S. Evaluation of grape ripeness, carbonic maceration and pectolytic enzymes to improve the chemical and sensory quality of red sparkling wines. J. Sci. Food Agric. 2020, 100, 2618-2629. [CrossRef]

97. Trouillas, P.; Sancho-García, J.C.; De Freitas, V.; Gierschner, J.; Otyepka, M.; Dangles, O. Stabilizing and Modulating Color by Copigmentation: Insights from Theory and Experiment. Chem. Rev. 2016, 116, 4937-4982. [CrossRef] 
98. Fernandes, A.; Oliveira, J.; Teixeira, N.; Mateus, N.; De Freitas, V. A review of the current knowledge of red wine colour. J. Int. Sci. Vigne Vin 2017, 51,1-21.

99. Darias-Martín, J.; Carrillo, M.; Díaz, E.; Boulton, R.B. Enhancement of red wine colour by pre-fermentation addition of copigments. Food Chem. 2001, 73, 217-220. [CrossRef]

100. Li, Y.; Prejanò, M.; Toscano, M.; Russo, N. Oenin and Quercetin Copigmentation: Highlights From Density Functional Theory. Front. Chem. 2018, 6, 245. [CrossRef]

101. Heras-Roger, J.; Díaz-Romero, C.; Darias-Martín, J. What Gives a Wine Its Strong Red Color? Main Correlations Affecting Copigmentation. J. Agric. Food Chem. 2016, 64, 6567-6574. [CrossRef]

102. Zhang, B.; Yang, X.S.; Li, N.N.; Zhu, X.; Sheng, W.J.; He, F.; Duan, C.Q.; Han, S.Y. Colorimetric study of malvidin-3-O-glucoside copigmented by phenolic compounds: The effect of molar ratio, temperature, $\mathrm{pH}$, and ethanol content on color expression of red wine model solutions. Food Res. Int. 2017, 102, 468-477. [CrossRef] [PubMed]

103. Zhang, B.; Wang, Q.; Zhou, P.-P.; Li, N.-N.; Han, S.-Y. Copigmentation evidence of oenin with phenolic compounds: A comparative study of spectrographic, thermodynamic and theoretical data. Food Chem. 2020, 313, 126163. [CrossRef] [PubMed]

104. Kanha, N.; Surawang, S.; Pitchakarn, P.; Regenstein, J.M.; Laokuldilok, T. Copigmentation of cyanidin 3-O-glucoside with phenolics: Thermodynamic data and thermal stability. Food Biosci. 2019, 30, 100419. [CrossRef]

105. Bimpilas, A.; Panagopoulou, M.; Tsimogiannis, D.; Oreopoulou, V. Anthocyanin copigmentation and color of wine: The effect of naturally obtained hydroxycinnamic acids as cofactors. Food Chem. 2016, 197, 39-46. [CrossRef] [PubMed]

106. Claus, H.; Mojsov, K. Enzymes for wine fermentation: Current and perspective applications. Fermentation 2018, 4, 52. [CrossRef]

107. Fernández, K.; Vega, M.; Aspé, E. An enzymatic extraction of proanthocyanidins from País grape seeds and skins. Food Chem. 2015, 168, 7-13. [CrossRef]

108. Grieco, F.; Carluccio, M.A.; Giovinazzo, G. Autochthonous Saccharomyces cerevisiae Starter. Foods 2019, 8, 453. [CrossRef]

109. Monagas, M.; Bartolomé, B. Anthocyanins and anthocyanin-derived compounds. In Wine Chemistry and Biochemistry; Springer: New York, NY, USA, 2009; pp. 439-462. ISBN 9780387741161.

110. Morata, A.; Gómez-Cordovés, M.C.; Colomo, B.; Suárez, J.A. Cell wall anthocyanin adsorption by different Saccharomyces strains during the fermentation of Vitis vinifera L. cv Graciano grapes. Eur. Food Res. Technol. 2005, 220, 341-346. [CrossRef]

111. Maza, M.; Álvarez, I.; Raso, J. Thermal and Non-Thermal Physical Methods for Improving Polyphenol Extraction in Red Winemaking. Beverages 2019, 5, 47. [CrossRef]

112. Clodoveo, M.L.; Dipalmo, T.; Rizzello, C.G.; Corbo, F.; Crupi, P. Emerging technology to develop novel red winemaking practices: An overview. Innov. Food Sci. Emerg. Technol. 2016, 38, 41-56. [CrossRef]

113. Morata, A.; Loira, I.; Vejarano, R.; González, C.; Callejo, M.J.; Suárez-Lepe, J.A. Emerging preservation technologies in grapes for winemaking. Trends Food Sci. Technol. 2017, 67, 36-43. [CrossRef]

114. Ricci, A.; Parpinello, G.P.; Versari, A. Recent advances and applications of pulsed electric fields (PEF) to improve polyphenol extraction and color release during red winemaking. Beverages 2018, 4, 18. [CrossRef]

115. Nioi, C.; Lisanti, M.T.; Lacampagne, S.; Noilet, P.; Mietton Peuchot, M.; Ghidossi, R. Nanofiltration process as non-thermal alternative to thermovinification in Pinot noir winemaking. OENO ONE 2020, 54, 37-47. [CrossRef]

116. Cassano, A.; Conidi, C.; Castro-Muñoz, R. Current and Future Applications of Nanofiltration in Food Processing. In Separation of Functional Molecules in Food by Membrane Technology; Elsevier: London, UK, 2019; pp. 305-348.

117. Yammine, S.; Rabagliato, R.; Vitrac, X.; Peuchot, M.M.; Ghidossi, R. The use of nanofiltration membranes for the fractionation of polyphenols from grape pomace extracts. OENO ONE 2019, 53, 11-26. [CrossRef]

118. Maza, M.A.; Martínez, J.M.; Hernández-Orte, P.; Cebrián, G.; Sánchez-Gimeno, A.C.; Álvarez, I.; Raso, J. Influence of pulsed electric fields on aroma and polyphenolic compounds of Garnacha wine. Food Bioprod. Process. 2019, 116, 249-257. [CrossRef]

119. OIV (Organisation International de la Vigne et du Vin) HPLC-Determination of nine major anthocyanins in red and rosé wine, Method OIV-MA-AS315-11. OIV Method 2007, 2007, 1-13. 
120. Diamantidou, D.; Zotou, A.; Theodoridis, G. Wine and grape marc spirits metabolomics. Metabolomics 2018, 14, 159. [CrossRef]

121. Wishart, D.S. NMR metabolomics: A look ahead. J. Magn. Reson. 2019, 306, 155-161. [CrossRef]

122. Emwas, A.-H.M. The strengths and weaknesses of NMR spectroscopy and mass spectrometry with particular focus on metabolomics research. In Metabonomics; Springer: Berlin, Germany, 2015; pp. 161-193.

123. Flamini, R. Recent Applications of Mass Spectrometry in the Study of Grape and Wine Polyphenols. ISRN Spectrosc. 2013, 2013, 813563. [CrossRef]

124. Arapitsas, P.; Ugliano, M.; Marangon, M.; Piombino, P.; Rolle, L.; Gerbi, V.; Versari, A.; Mattivi, F. Use of untargeted LC-MS metabolome to discriminate Italian mono-varietal red wines, produced in their different terroirs. J. Agric. Food Chem. 2020. [CrossRef]

125. OIV Compendium of International Methods of Analysis: Alcoholic Strength by Volume (Resolution Oeno 566/2016). OIV-MA-AS312-01A. Available online: http://www.oiv.int (accessed on 12 August 2020).

126. OIV Compendium of International Methods of Analysis: Reducing Substances. OIV-MA-AS311-01A. Available online: http://www.oiv.int (accessed on 12 August 2020).

127. OIV Compendium of International Methods of Analysis: Total Acidity. OIV-MA-AS313-01. Available online: http://www.oiv.int (accessed on 12 August 2020).

128. OIV Compendium of International Methods of Analysis: Volatile Acidity (A 11, Revised by 377/2009). OIV-MA-AS313-02. Available online: http://www.oiv.int (accessed on 12 August 2020).

129. OIV Compendium of International Methods of Analysis: Sulphur Dioxide (Iodometry) (A 17 Revised by 377/2009). OIV-MA-AS323-04B. Available online: http://www.oiv.int (accessed on 12 August 2020).

130. OIV Compendium of International Methods of Analysis: Analysis of Volatile Compounds in Wines by Gas Chromatography (Resolution OIV-OENO 553/2016). OIV-MA-AS315-27. Available online: http://www.oiv.int (accessed on 12 August 2020).

131. OIV Compendium of International Methods of Analysis: Determination of the Principal Organic Acids of Wines and Sulphates by Capillary Electrophoresis. OIV-MA-AS313-19. Available online: http://www.oiv.int (accessed on 12 August 2020).

132. OIV Compendium of International Methods of Analysis: Analysis of Mineral Elements in Wines Using ICP-AES (Inductively Coupled Plasma/Atomic Emission Spectrometry) (Oeno 478/2013). OIV-MA-AS322-13. Available online: http://www.oiv.int (accessed on 12 August 2020).

133. OIV Compendium of International Methods of Analysis: Determination by Isotope Ratio Mass Spectometry $13 \mathrm{C} / 12 \mathrm{C}$ of Wine Ethanol or that Obtained through the Fermentation of Musts, Concentrated Musts or Grape Sugar. OIV-MA-AS312-06. Available online: http://www.oiv.int (accessed on 12 August 2020).

134. OIV Compendium of International Methods of Analysis: Determination of the Deuterium Distribution in Ethanol Derived from Fermentation of Grape Musts, Concentrated Grape Musts, Grape Sugar (Rectified Concentrated Grape Musts) and Wines by Application of Nuclea. Available online: http://www.oiv.int (accessed on 12 August 2020).

135. OIV Compendium of International Methods of Analysis: Examination of Artificial Sweeteners (a) OIV-MA-AS315-07A. Available online: http://www.oiv.int (accessed on 12 August 2020).

136. OIV Compendium of International Methods of Analysis: Examination of Artificial Colorants. OIV-MA-AS315-08. Available online: http://www.oiv.int (accessed on 12 August 2020).

137. OIV Compendium of International Methods of Analysis: Detection of Preservatives and Fermentation Inhibitors (Detection of Sorbic, Benzoic, p-chlorobenzoic, Salicylic Acids and p-hydrobenzoic Acid and Its Esters) (A35; Oeno 6/2006; Revised by 377/2009). OIV-MA. Available online: http://www.oiv.int (accessed on 12 August 2020).

138. OIV Compendium of International Methods of Analysis: Folin-Ciocalteu Index. OIV-MA-AS2-10. Available online: http://www.oiv.int (accessed on 12 August 2020).

139. OIV Compendium of International Methods of Analysis: Determination of Nine Major Anthocyanins in Red and Rosé Wines Using HPLC (Oeno 22/2003, Oeno 12/2007). OIV-MA-AS315-11. Available online: http://www.oiv.int (accessed on 12 August 2020).

140. OIV Compendium of International Methods of Analysis: Malvidin Diglucoside. OIV-MA-AS315-03. Available online: http://www.oiv.int (accessed on 12 August 2020). 
141. Locatelli, M.; Travaglia, F.; Coïsson, J.D.; Bordiga, M.; Arlorio, M. Phenolic composition of Nebbiolo grape (Vitis vinifera L.) from Piedmont: Characterization during ripening of grapes selected in different geographic areas and comparison with Uva Rara and Vespolina cv. Eur. Food Res. Technol. 2016, 242, 1057-1068. [CrossRef]

142. Pisano, P.L.; Silva, M.F.; Olivieri, A.C. Anthocyanins as markers for the classification of Argentinean wines according to botanical and geographical origin. Chemometric modeling of liquid chromatography-mass spectrometry data. Food Chem. 2015, 175, 174-180. [CrossRef] [PubMed]

143. De Rosso, M.; Mayr, C.M.; Girardi, G.; Vedova, A.D.; Flamini, R. High-resolution mass spectrometry metabolomics of grape chemical markers to reveal use of not-allowed varieties in the production of Amarone and Recioto wines. Metabolomics 2018, 14, 124. [CrossRef] [PubMed]

144. Stój, A.; Kapusta, I.; Domagała, D. Classification of Red Wines Produced from Zweigelt and Rondo Grape Varieties Based on the Analysis of Phenolic Compounds by UPLC-PDA-MS/MS. Molecules 2020, 25, 1342. [CrossRef]

145. Savino, M.; Basile, T.; Alba, V.; Bolettieri, D.; Paradiso, F.; Tamborra, P.; Suriano, S.; Tarricone, L. Detection of Intra-Varietal Diversity Based on Differences in the Accumulation of Secondary Metabolites for Winemaking Management of High-Quality Red Wines. Beverages 2017, 3, 45. [CrossRef]

146. Gil, M.; Reynes, C.; Cazals, G.; Enjalbal, C.; Sabatier, R.; Saucier, C. Discrimination of rosé wines using shotgun metabolomics with a genetic algorithm and MS ion intensity ratios. Sci. Rep. 2020, 10, 1-7. [CrossRef]

147. Rocchetti, G.; Gatti, M.; Bavaresco, L.; Lucini, L. Untargeted metabolomics to investigate the phenolic composition of Chardonnay wines from different origins. J. Food Compos. Anal. 2018, 71, 87-93. [CrossRef]

148. Longo, E.; Rossetti, F.; Jouin, A.; Teissedre, P.L.; Jourdes, M.; Boselli, E. Distribution of crown hexameric procyanidin and its tetrameric and pentameric congeners in red and white wines. Food Chem. 2019, 299, 125125. [CrossRef]

149. Alves Filho, E.G.; Silva, L.M.A.; Ribeiro, P.R.V.; de Brito, E.S.; Zocolo, G.J.; Souza-Leão, P.C.; Marques, A.T.B.; Quintela, A.L.; Larsen, F.H.; Canuto, K.M. ${ }^{1} \mathrm{H}$ NMR and LC-MS-based metabolomic approach for evaluation of the seasonality and viticultural practices in wines from São Francisco River Valley, a Brazilian semi-arid region. Food Chem. 2019, 289, 558-567. [CrossRef]

150. Tassoni, A.; Tango, N.; Ferri, M. Comparison of biogenic amine and polyphenol profiles of grape berries and wines obtained following conventional, organic and biodynamic agricultural and oenological practices. Food Chem. 2013, 139, 405-413. [CrossRef]

151. Picone, G.; Trimigno, A.; Tessarin, P.; Donnini, S.; Rombolà, A.D.; Capozzi, F. ${ }^{1} \mathrm{H}$ NMR foodomics reveals that the biodynamic and the organic cultivation managements produce different grape berries (Vitis vinifera L. cv. Sangiovese). Food Chem. 2016, 213, 187-195. [CrossRef] [PubMed]

152. Parpinello, G.P.; Rombolà, A.D.; Simoni, M.; Versari, A. Chemical and sensory characterisation of Sangiovese red wines: Comparison between biodynamic and organic management. Food Chem. 2015, 167, 1-8. [CrossRef] [PubMed]

153. Parpinello, G.P.; Ricci, A.; Rombolà, A.D.; Nigro, G.; Versari, A. Comparison of Sangiovese wines obtained from stabilized organic and biodynamic vineyard management systems. Food Chem. 2019, 283, 499-507. [CrossRef] [PubMed]

154. Arapitsas, P.; Scholz, M.; Vrhovsek, U.; Di Blasi, S.; Biondi Bartolini, A.; Masuero, D.; Perenzoni, D.; Rigo, A.; Mattivi, F. A metabolomic approach to the study of wine micro-oxygenation. PLoS ONE 2012, 7, e37783. [CrossRef]

155. Herbert-Pucheta, J.E.; Padilla-Maya, G.; Milmo-Brittinham, D.; Lojero, D.; Gilmore, A.M.; Raventós-Llopart, L.; Hernández-Pulido, K.E.; Zepeda-Vallejo, L.G. Multivariate spectroscopy for targeting phenolic choreography in wine with A-TEEM TM and NMR crosscheck non-targeted metabolomics. BIO Web Conf. 2019, 15, 02006. [CrossRef]

156. Arapitsas, P.; Della Corte, A.; Gika, H.; Narduzzi, L.; Mattivi, F.; Theodoridis, G. Studying the effect of storage conditions on the metabolite content of red wine using HILIC LC-MS based metabolomics. Food Chem. 2016, 197, 1331-1340. [CrossRef]

157. Willemse, C.M.; Stander, M.A.; Vestner, J.; Tredoux, A.G.J.; De Villiers, A. Comprehensive Two-Dimensional Hydrophilic Interaction Chromatography $($ HILIC) $\times$ Reversed-Phase Liquid Chromatography Coupled to High-Resolution Mass Spectrometry (RP-LC-UV-MS) Analysis of Anthocyanins and Derived Pigments in Red Wine. Anal. Chem. 2015, 87, 12006-12015. [CrossRef] 
158. Alañón, M.E.; Pérez-Coello, M.S.; Marina, M.L. Wine science in the metabolomics era. TrAC-Trends Anal. Chem. 2015, 74, 1-20. [CrossRef]

159. Roullier-Gall, C.; Kanawati, B.; Hemmler, D.; Druschel, G.K.; Gougeon, R.D.; Schmitt-Kopplin, P. Electrochemical triggering of the Chardonnay wine metabolome. Food Chem. 2019, 286, 64-70. [CrossRef]

160. Gougeon, L.; da Costa, G.; Guyon, F.; Richard, T. 1H NMR metabolomics applied to Bordeaux red wines. Food Chem. 2019, 301, 125257. [CrossRef]

161. Gougeon, L.; da Costa, G.; Richard, T.; Guyon, F. Wine Authenticity by Quantitative 1 H NMR Versus Multitechnique Analysis: A Case Study. Food Anal. Methods 2019, 12, 956-965. [CrossRef]

162. Ruocco, S.; Stefanini, M.; Stanstrup, J.; Perenzoni, D.; Mattivi, F.; Vrhovsek, U. The metabolomic profile of red non- V. vinifera genotypes. Food Res. Int. 2017, 98, 10-19. [CrossRef] [PubMed]

163. Geana, E.I.; Popescu, R.; Costinel, D.; Dinca, O.R.; Ionete, R.E.; Stefanescu, I.; Artem, V.; Bala, C. Classification of red wines using suitable markers coupled with multivariate statistic analysis. Food Chem. 2016, 192, 1015-1024. [CrossRef] [PubMed]

164. Gougeon, L.; Da Costa, G.; Le Mao, I.; Ma, W.; Teissedre, P.L.; Guyon, F.; Richard, T. Wine Analysis and Authenticity Using 1H-NMR Metabolomics Data: Application to Chinese Wines. Food Anal. Methods 2018, 11, 3425-3434. [CrossRef]

165. Zhu, J.; Hu, B.; Lu, J.; Xu, S. Analysis of metabolites in cabernet sauvignon and shiraz dry red wines from Shanxi by $1 \mathrm{H}$ NMR spectroscopy combined with pattern recognition analysis. Open Chem. 2018, 16, 446-452. [CrossRef]

166. Cassino, C.; Tsolakis, C.; Bonello, F.; Gianotti, V.; Osella, D. Effects of area, year and climatic factors on Barbera wine characteristics studied by the combination of ${ }^{1} \mathrm{H}-\mathrm{NMR}$ metabolomics and chemometrics. J. Wine Res. 2017, 28, 259-277. [CrossRef]

167. Powers, R.; Riekeberg, E. New frontiers in metabolomics: From measurement to insight. F1000Research 2017, 6, 1148.

168. O'Shea, K.; Misra, B.B. Software tools, databases and resources in metabolomics: Updates from 2018 to 2019. Metabolomics 2020, 16, 36. [CrossRef]

169. Li, Z.; Lu, Y.; Guo, Y.; Cao, H.; Wang, Q.; Shui, W. Comprehensive evaluation of untargeted metabolomics data processing software in feature detection, quantification and discriminating marker selection. Anal. Chim. Acta 2018, 1029, 50-57. [CrossRef]

170. Blaženović, I.; Kind, T.; Ji, J.; Fiehn, O. Software tools and approaches for compound identification of LC-MS/MS data in metabolomics. Metabolites 2018, 8, 31. [CrossRef]

171. Portinale, L.; Leonardi, G.; Arlorio, M.; Coïsson, J.D.; Travaglia, F.; Locatelli, M. Authenticity assessment and protection of high-quality Nebbiolo-based Italian wines through machine learning. Chemom. Intell. Lab. Syst. 2017, 171, 182-197. [CrossRef]

172. Kopka, J.; Walther, D.; Allwood, J.W.; Goodacre, R. Progress in Chemometrics and Biostatistics for Plant Applications, or: A Good Red Wine is a Bad White Wine. In Annual Plant Reviews Online; John Wiley \& Sons, Ltd.: Chichester, UK, 2018; pp. 317-342.

(C) 2020 by the authors. Licensee MDPI, Basel, Switzerland. This article is an open access article distributed under the terms and conditions of the Creative Commons Attribution (CC BY) license (http://creativecommons.org/licenses/by/4.0/). 